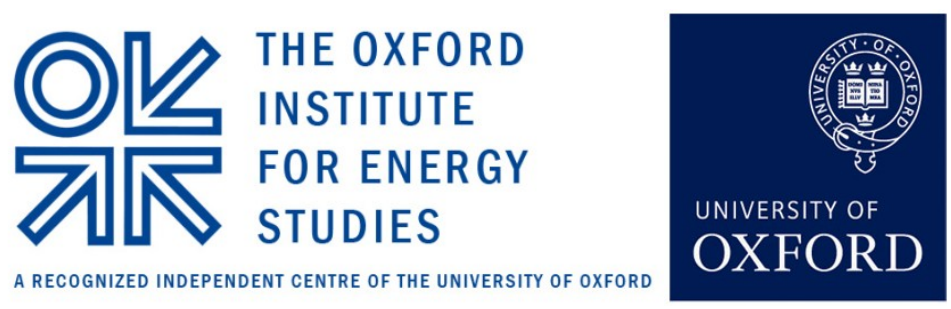

\title{
Will There Be a Shale Gas Revolution in China by 2020 ?
}

\author{
Fan Gao
}

NG 61

April 2012 
The contents of this paper are the authors' sole responsibility. They do not necessarily represent the views of the Oxford Institute for Energy Studies or any of its members.

Copyright (C) 2012

Oxford Institute for Energy Studies

(Registered Charity, No. 286084)

This publication may be reproduced in part for educational or non-profit purposes without special permission from the copyright holder, provided acknowledgment of the source is made. No use of this publication may be made for resale or for any other commercial purpose whatsoever without prior permission in writing from the Oxford Institute for Energy Studies.

ISBN

978-1-907555-45-9 


\section{Preface}

China's gas demand grew by a factor of four in the 2000s as it joined the ranks of the major industrialised gas consuming economies. With gas representing less than $4 \%$ of its primary energy consumption and economic growth continuing apace, the expectation is that gas demand will continue to grow, enhanced by a desire to improve air quality and mitigate other tangible environmental impacts of heavy reliance on coal in the energy mix. While domestic gas production has also grown considerably, China has already accepted the need to import pipeline gas from Turkmenistan and Myanmar and LNG from a variety of suppliers in order to meet its requirements.

In addition to its conventional gas resource endowment, China is assessed as having the third largest Coal Bed Methane resources and, of the countries included in a 2011 EIA assessment of international potential, the highest shale gas resources. Clearly unconventional gas should play a significant role in contributing towards China's future energy needs.

This research by Fan Gao cautions against optimistic assumptions of a rapid acceleration of shale gas production prior to 2020. This is based on a review of the rather disappointing progress on Coal Bed Methane production since exploration and development work started some 25 years ago. The reasons contributing to this are identified and discussed and the insights are applied to the question of how China might achieve material production levels of shale gas production by 2020 . The challenges include water availability and population density demographics as well as the need to stimulate an innovative competitive dynamic in the Chinese upstream service sector and an appropriate upstream investment framework with foreign participants for the transfer and application of technology.

The paper provides a rare appreciation of the dynamics of the onshore Chinese upstream industry and from that basis a better understanding of what will be required for Chinese shale gas development to succeed.

Howard V Rogers

April 2012 


\section{Contents}

Abbreviations, acronyms and units.................................................................................................v

1. Introduction: The Chinese Natural Gas Market - An Overview........................................1

2. Why did China fail to meet its coal bed methane targets? ................................................6

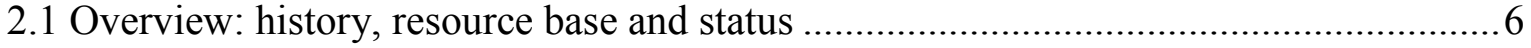

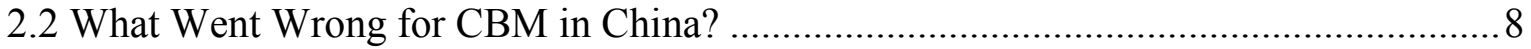

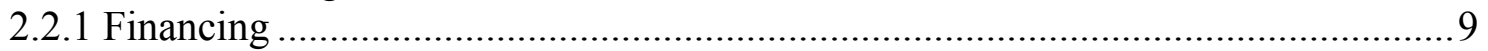

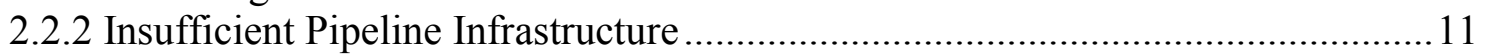

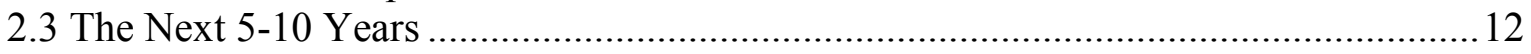

3. Shale Gas Development in China: an overview ...........................................................16

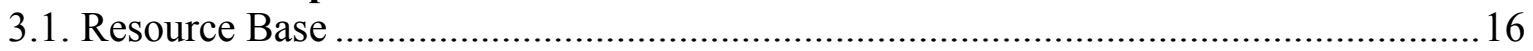

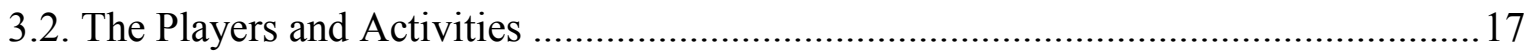

4. Will Shale Gas production in China take off by 2020? .....................................................22

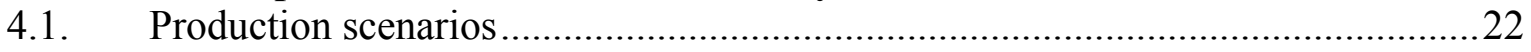

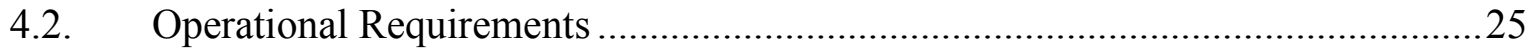

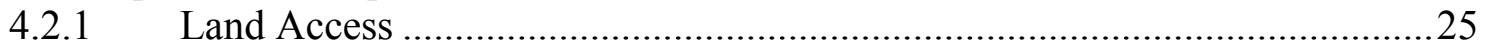

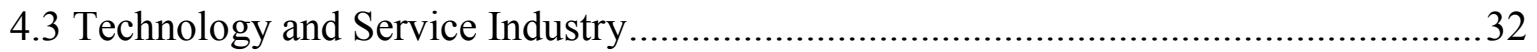

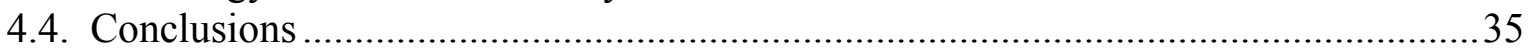

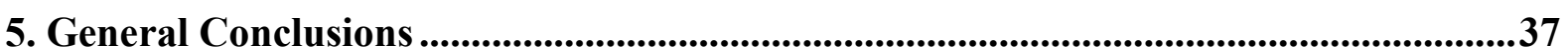

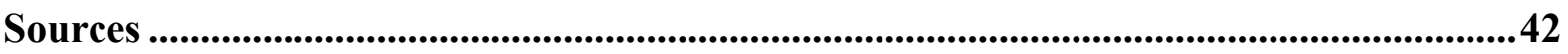

\section{Tables, figures and maps}

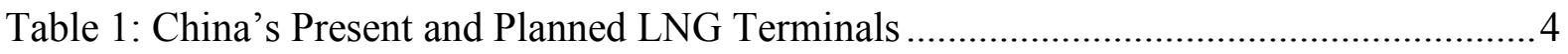

Table 2: CUCBM's Foreign Partners for CBM projects. ..................................................... 10

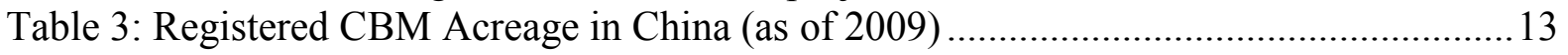

Table 4: CBM Production Targets Set by the Government and Chinese NOCs .................... 14

Table 5: Foreign Players and their Shale Gas Activities in China........................................ 18

Table 6: Shale Gas Production Plans Announced by NOCs and the Government .................23

Table 7: Annual Water Usage for Maintaining $50 \mathrm{Bcm} / \mathrm{y}$ Production over 10 Years .............29

Table 8: Per Capita Water Availability (Total Renewable Water Resources) (m³/capita/year)

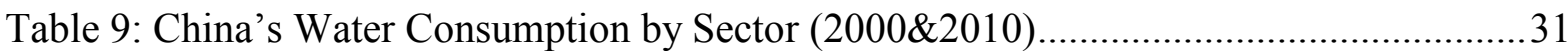

Table 10: China Natural Gas Supply and Demand (2011-2020) (Unit: Bcm) .......................40

Figure 1: Natural Gas Production and Consumption in China 2001-2010 .............................. 1

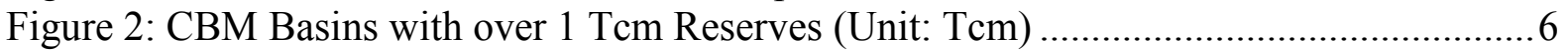

Figure 3: Drilling Plan for the 30/50/80 Bcm/y Scenarios .................................................. 24

Figure 4: How to Produce $50 \mathrm{Bcm} / \mathrm{y}$ in 8 Years and Sustain Production for 10 Years...........25

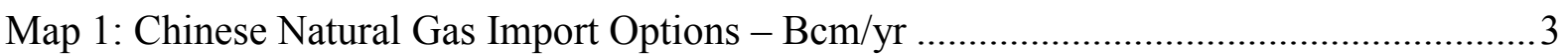

Map 2: Coalbed Methane Resources Distribution in China (Unit: Tcm) .............................. 7

Map 3: Major Shale Gas Basins and Pipeline System of China ........................................... 16

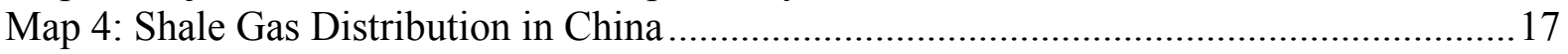

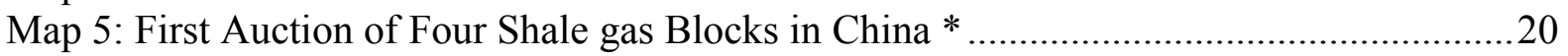

Map 6: Population Density of China and the World. (2000) ............................................... 27

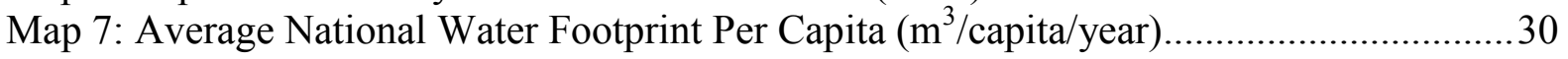

Map 8: Precipitation and Distribution of Water Resources ................................................. 32 


\section{Abbreviations, acronyms and units}

Aquastat - the United Nations' Food and Agriculture Organization's global information system on water and agriculture

Bcm - Billion cubic metres

CBM - Coal Bed Methane

CMM - Coal Mine Methane

CNOOC - China National Offshore Oil Corporation

CNPC - China National Petroleum Corporation

CUCBM - China United Coal Bed Methane Corporation

EIA - (US) Energy Information Administration

EPA - (US) Environmental Protection Agency

IOC - International Oil Company

ISC - International Service Company

LWD - Logging While Drilling

Mcf - Thiusand Cubic Feet

MLR - Ministry of Land Resources

MMBtu - Million British Thermal Units

MMcf/d - Million Cubic Feet per day

Mtoe - Million tonnes of oil equivalent

Mtpa - Million tonnes of LNG/year

NDRC - National Development and Reform Commission

NEA - National Energy Administration

NOC - National Oil Company

NSC - National Service Company

OBM - Oil Based Mud

RMB - (Renminbi) the official currency of the Republic of China - US\$0.1585 on March 5 2012

Sinopec - China Petrochemical Corporation

Tcf - Trillion cubic feet

Tcm - Trillion cubic metres 


\section{Introduction: The Chinese Natural Gas Market - An Overview}

China's total primary energy consumption reached 2,432 Mtoe (excluding Hong Kong) in 2010, exceeding the United States to become the world's largest energy consumer. ${ }^{1}$ Meanwhile, China's natural gas consumption increased by nearly $21.8 \%$ to $109 \mathrm{Bcm}$ in 2010 , making it the fourth largest gas consumer in the world after the US, Russia and Iran. While China is one of the biggest natural gas consumers in absolute terms, it accounts for only a small proportion (less than 4\%) of China's primary energy mix, compared to the global average level of $24 \% .^{2}$

The Chinese natural gas industry has a relatively short history. China started producing natural gas in 1949 and for a long time the Sichuan Basin was the only major gas producing region. Output remained at less than $30 \mathrm{Bcm} / \mathrm{y}$ for more than a half century. For a few decades, natural gas did not grow into an important source of energy fuelling China's rapid economic growth, but in the 1980s and 1990s, intensive exploration activities began to bear fruit. Major gas basins, including six onshore basins (Sichuan, Ordos, Tarim, Qaidam, Songliao, Zhunggar basin) and two offshore basins (South China Sea and East China Sea basin) were discovered. Gas reserves have been rising at $100 \mathrm{Bcm} / \mathrm{y}$ since the $1990 \mathrm{~s}$, and this has laid a solid foundation for the expansion of China's natural gas industry. As of 2007, China's proven gas reserves had reached 5.94 trillion cubic metres $(\mathrm{Tcm})$ whereas the recoverable reserves were $3.66 \mathrm{Tcm}^{3}$. (MLR, 2010)

Figure 1: Natural Gas Production and Consumption in China 2001-2010

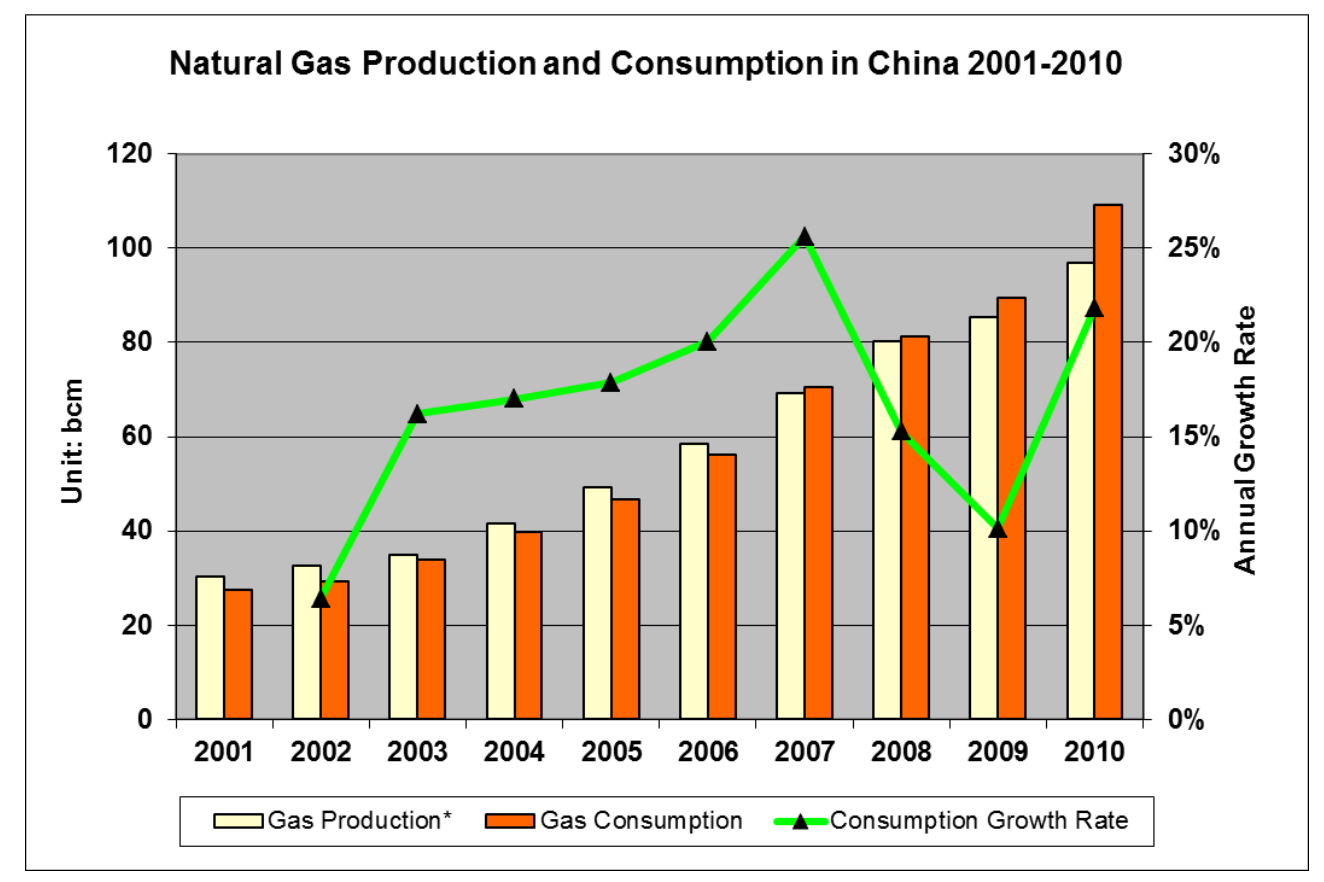

Source: BP Statistical Review 2011

China has only seen significant growth in both gas production and consumption in the $21^{\text {st }}$ century. As Figure 1 shows, for over a decade, production grew at 13.5\%/y from $27.2 \mathrm{Bcm}$ in

\footnotetext{
${ }^{1}$ BP 2011(BP Statistical Review of World Energy 2011)

${ }^{2}$ MLR 2010 ( Ministry of Land and Resources, 2010)

${ }^{3}$ MLR2010
} 
2000 to $96.8 \mathrm{Bcm}$ in 2010 . Gas demand has been growing even faster by around $20 \% / \mathrm{y}$ since 2007 thanks to a fast growing economy and rising living standards. Although gas remains expensive compared to coal, regulated gas prices make this relatively clean fossil fuel competitive against oil. Consumers in the coastal cities, far from the major coal producing areas in north and west China, are willing to accept higher gas prices in exchange for higher energy efficiency and better air quality.

As China entered a new decade of fast growth in energy consumption, domestic gas production could no longer satisfy industrial and residential needs for more gas. Soaring energy prices and China's increasing concern about deteriorating environmental conditions pushed the country even further in the direction of gas. However, in general terms, natural gas in China is trapped in smaller and less favourable reservoirs that are more difficult to access compared with other gas-rich countries such as Russia, Venezuela, Qatar, etc. As a country new to gas development, lack of expertise, technology and infrastructure also significantly restricted the speed with which the resource has been explored and developed.

To bridge the gap between domestic supply and demand, China was forced to seek foreign supplies. Over the past decade, China's natural gas market has gradually moved from selfsufficiency to increasing dependence on imports. This trend is projected to continue over the next 20 years. Consequently, China has been actively securing stable and long term supplies both by pipeline from neighbouring central Asian countries and as LNG imports from a variety of overseas sources.

In 2002, China started to build its first long-distance trunk pipeline - the West-East Pipeline - to transport domestic and Central Asia gas from China's western border to the end users in the south-east regions. China signed a long term contract with Turkmenistan in 2006 for deliveries of up to $40 \mathrm{Bcm} /$ year of gas for a 30 year period. As of 2011, China has imported a total of $17 \mathrm{Bcm}$ of gas from Turkmenistan via the West-East Pipeline, a figure expected to reach $30 \mathrm{Bcm} / \mathrm{y}$ by 2015 . In 2011, the two countries agreed to increase supplies of Turkmen natural gas to China to $65 \mathrm{Bcm} / \mathrm{y}$.

In late 2008, China and Myanmar agreed to build a natural gas pipeline with a capacity of 12 $\mathrm{Bcm} / \mathrm{y}$, which is expected to be brought on stream by the end of 2012. In early 2012, China's total contracted pipeline gas has reached $77 \mathrm{Bcm} / \mathrm{y}$. China has also been in talks with Russia for possible pipeline gas imports from either West Siberia or East Siberia to its borders, so far without success.

Meanwhile, China concluded long term liquefied natural gas supply contracts and built regasification capacity to receive LNG from major gas exporting countries such as Australia, Qatar, Malaysia and Indonesia. In May 2006, China received the first LNG cargo arriving at Dapeng Terminal in Guangdong province. Five years later in 2010, China's LNG imports reached 9.36 million tonnes/y (approximately $12.9 \mathrm{Bcm}$ ). By end of 2011, the country had five LNG receiving terminals in operation while a dozen more were under construction or planned. In 2011, China received 12.2 million tonnes (approximately $16.8 \mathrm{Bcm}$ ) of LNG cargoes, $30 \%$ higher than in 2010. As Table 1 shows, China has five terminals in operation, eight under construction, and six more approved. According to the plans the total receiving capacity at these terminals will reach $44 \mathrm{mtpa}(60.7 \mathrm{Bcm} / \mathrm{y})^{4}$ by 2015 .

\footnotetext{
${ }^{4} 1 \mathrm{mtpa}$ of $\mathrm{LNG}=1.38 \mathrm{Bcm} /$ year
} 


\section{Map 1: Chinese Natural Gas Import Options - Bcm/yr}

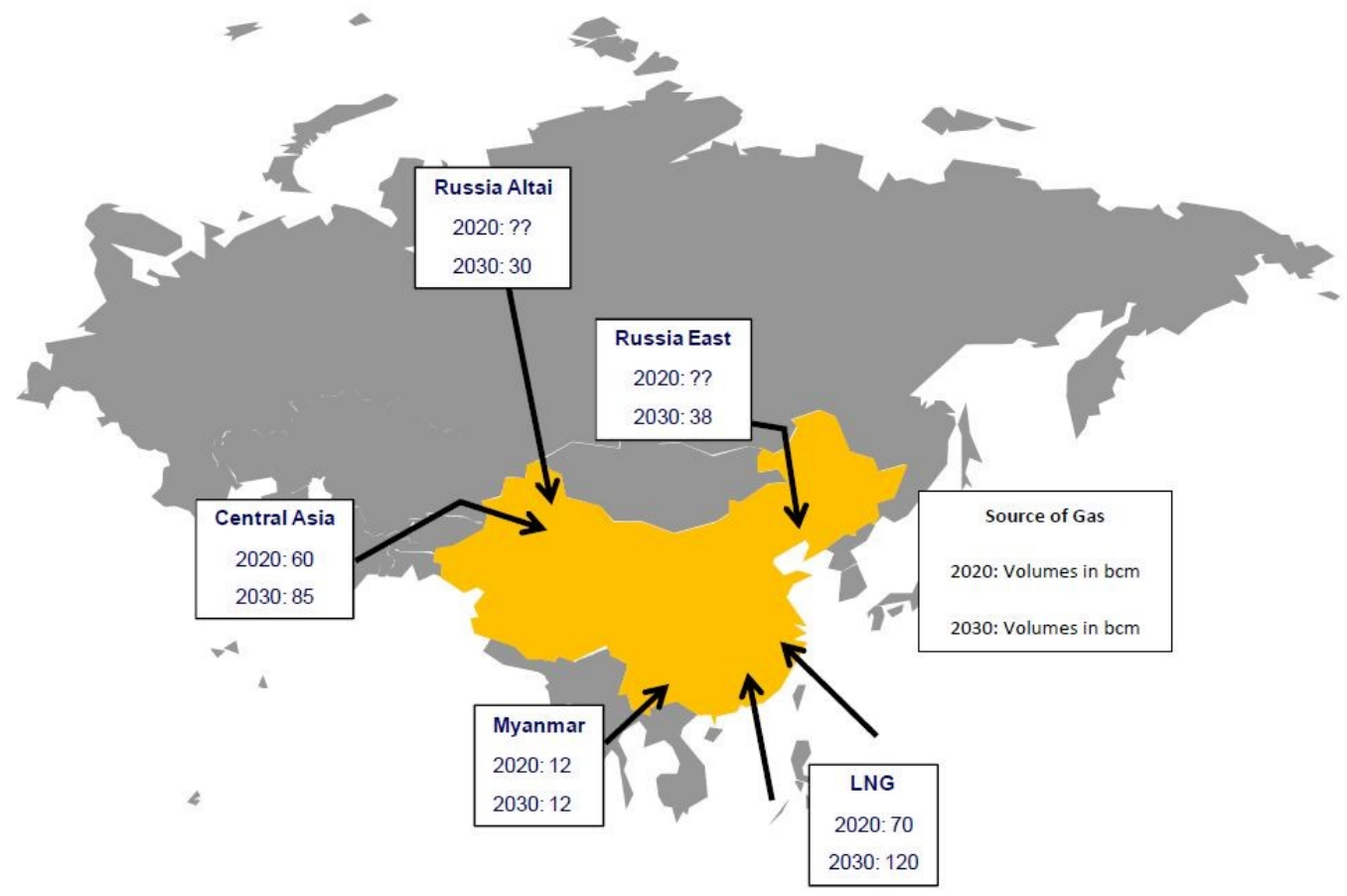

Source: Henderson, J. (2011). The Pricing Debate over Russian Gas Exports to China. NG 56. Oxford: OIES.

China's largest national oil and gas producer CNPC estimates China's gas demand will exceed $250 \mathrm{Bcm}$ by 2015 and approximately one third of this demand will have to be met by gas imports ${ }^{5}$. Industry experts expect the thirteenth Five Year Plan Period (2015-2020) will continue to observe fast growth of natural gas demand as the country continues to benefit from infrastructure improvements. By 2020 , demand could possibly reach $400 \mathrm{Bcm} / \mathrm{y}$ which could create a gap between domestic supply and demand of 120-160 Bcm. Although China has made efforts to accelerate its domestic gas production, it is expected that the dependence on gas imports will increase as a result of faster growing demand.

Being a large country desperate for energy to sustain its economic development, securing and diversifying oil and gas supplies has always been high on China's agenda. In the context of a widening gap between domestic supply and demand, Chinese oil and gas producers are keen to explore new sources of energy. With higher efficiency and lower $\mathrm{CO}_{2}$ emissions, natural gas has emerged as the best alternative to coal. The Chinese authorities have been promoting the use of "cleaner gas" as a substitute fuel for coal. In the twelfth FYP, the central government set the target to increase the natural gas share in the total primary energy consumption from $3.8 \%$ in 2010 to $8 \%$ by $2020^{6}$.

\footnotetext{
${ }^{5}$ Kang Zhang, China Energy News, Oct 2011

${ }^{6}$ NDRC, 2011
} 
Table 1: China's Present and Planned LNG Terminals

\begin{tabular}{|c|c|c|c|c|c|}
\hline & LNG Projects & Location & Investors & $\begin{array}{c}\text { Capacity } \\
\text { (million tonnes/year) }\end{array}$ & Start-up date \\
\hline 1 & Dapeng & Guangdong & $\mathrm{CNOOC}$ & 3.7 & 2006 \\
\hline 2 & Putian & Fujian & CNOOC & 2.6 & 2010 \\
\hline 3 & Shanghai & Shanghai & $\mathrm{CNOOC}$ & 3 & 2009 \\
\hline 4 & Rudong & Jiangsu & CNPC & 3.5 & 2011 \\
\hline 5 & Dalian & Liaoning & CNPC & 3 & 2011 \\
\hline 6 & Ningbo & Zhejiang & CNOOC & 3 & Under construction \\
\hline 7 & Hainan & Hainan & $\mathrm{CNOOC}$ & 3 & Under construction \\
\hline 8 & Zhuhai & Guangdong & $\mathrm{CNOOC}$ & 3.5 & Under construction \\
\hline 9 & Yuedong & Guangdong & $\mathrm{CNOOC}$ & 2 & Under construction \\
\hline 10 & Qingdao & Shandong & Sinopec & 3 & Under construction \\
\hline 11 & Tangshan & Hebei & CNPC & 6 & Under construction \\
\hline 12 & Dalian & Liaoning & CNPC & 2 & Under construction \\
\hline 13 & Qinhuangdao & Hebei & $\mathrm{CNOOC}$ & 2 & Approved \\
\hline 14 & Wenzhou & Zhejiang & CNOOC & 2 & Approved \\
\hline 15 & Yingkou & Liaoning & $\mathrm{CNOOC}$ & 3 & Pending for approval \\
\hline 16 & Shenzhen & Guangdong & CNPC & 6 & Under construction \\
\hline 17 & Binhai & Jiangsu & $\mathrm{CNOOC}$ & $\mathrm{N} / \mathrm{A}$ & Approved \\
\hline 18 & Shantou & Guangdong & CNOOC & 2.5 & Approved \\
\hline 19 & Qinzhou & Guangxi & CNPC & 3 & Approved \\
\hline 20 & Lianyungang & Jiangsu & Sinopec & N/A & Approved \\
\hline 21 & Tianjin & Tianjin & CNPC, CNOOC & N/A & Pending for approval \\
\hline
\end{tabular}

Source: CNPC, CNOOC, Sinopec websites

The rise of unconventional gas and the profound impact it has had on the North American gas market has aroused considerable interest in China. Tight gas, Coal Bed Methane (CBM) and shale gas, once too expensive to extract, have evolved into valuable sources of energy supply as technological advances and project optimisation significantly reduced their costs. The unconventional gas revolution in the United States provides a very attractive example for China to follow. Promoting unconventional gas could not only help China to moderate its increasingly high dependence on foreign gas, but could also have deeper implications for manufacturing industry, environmental conditions and the overall economic development. For these reasons, China has paid a great deal of attention to global unconventional gas trends.

Although unconventional gas arrived at a good time for the country in the planning of its future energy consumption, unconventional gas development remains nascent in China. Fifteen years of CBM developments produced very moderate results and China has yet to see any commercial shale gas production. In our view, there remain a number of obstacles to commercial development of unconventional gas in China. 
This study analyses whether China has created the conditions for significant unconventional gas (CBM, tight gas and shale gas) development that will have a noticeable impact on its domestic energy market and influence the global energy landscape. In Chapter 2 we look at the story of CBM development in China to see whether this may provide lessons for shale gas development. We then in Chapters 3 and 4 outline the progress of shale gas development so far, and systematically assess the operational and regulatory requirements of a shale gas production level that would substantially impact on Chinese and global gas markets. In Chapter 5 we draw general conclusions as to whether China will have a shale gas revolution by 2020 that will have significant implications for the gas industry, and provide suggestions for the creation of a successful framework for unconventional gas development. 


\section{Why did China fail to meet its coal bed methane targets?}

\subsection{Overview: history, resource base and status}

Extracting methane from coal seams is not new in China. The country started to remove methane from its coal mines as early as the 1950s following the start-up of its coal industry. Today China is the largest coal producing, as well as the largest coal consuming country, in the world. Despite early attempts, methane from coal seams was not considered as a source of primary energy, but a danger that kills over two thousand coal miners each year. ${ }^{7}$ As methane is highly combustible, measures have to be taken to dilute its density to a level below the explosive range. Roughly $15 \mathrm{Bcm} / \mathrm{y}$ of methane are vented or flared in the process of both surface and underground mining ${ }^{8}$. In recent years, China has seen significant growth in interest in the recovery and utilisation of CBM. One strong driver is the increasing movement worldwide to combat climate change. Methane is a potent greenhouse gas 23 times more harmful than carbon dioxide. Therefore, tackling the large volume of methane emissions from coal mining-related activities represents an important contribution for China to mitigate global warming. Meanwhile, as energy prices rise and natural gas demand soars in China, CBM has emerged as a valuable "unconventional" source of natural gas that would allow the country to further diversify its energy supplies.

Figure 2: CBM Basins with over 1 Tcm Reserves (Unit: Tcm)

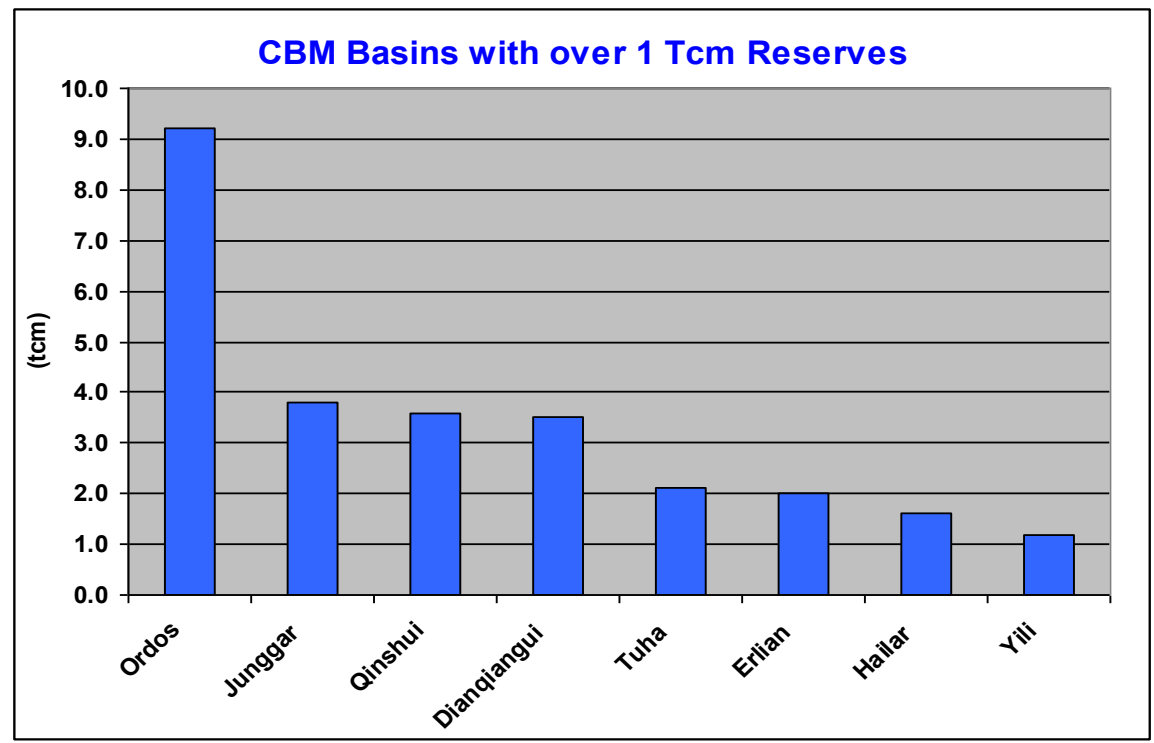

Source: CNPC's presentation at the Ninth Sino-US Oil and Gas Industry Forum. 2009

China is endowed with the third largest CBM resource base in the world, after Russia and Canada ${ }^{9}$. According to the latest National Petroleum Assessment $(2003-2007)^{10}$, China's total CBM resources at depths up to 2,000 metres are $37 \mathrm{Tcm}$ and recoverable reserves at depths up to 1,500 metres are estimated at $11 \mathrm{Tcm}$. In other words, CBM resources are at the same level as those of conventional gas. As demonstrated in Map 2, major CBM basins (with reserves above $1 \mathrm{Tcm}$ ) include Ordos, Qinshui, Junggar, Diandongqianxi, Erlian, Tuha,

\footnotetext{
${ }^{7}$ China State Administration of Coal Mine Safety, 2010.

${ }^{8}$ Shengchu Huang, China Coal Information Institute. 2008

${ }^{9}$ World Coal Association.

${ }^{10}$ Adapted from presentation at AAPG International Conference and Exhibition, Calgary, Canada, September 12-15, 2010. Also see Figure 1.
} 
Tarim, Tianshan and Hailar Basin. Ordos Basin and Junggar Basin in North China have the most abundant resources while most CBM developments have so far taken place in the Ordos and Qinshui Basins. ${ }^{11}$

\section{Map 2: Coalbed Methane Resources Distribution in China (Unit: Tcm)}

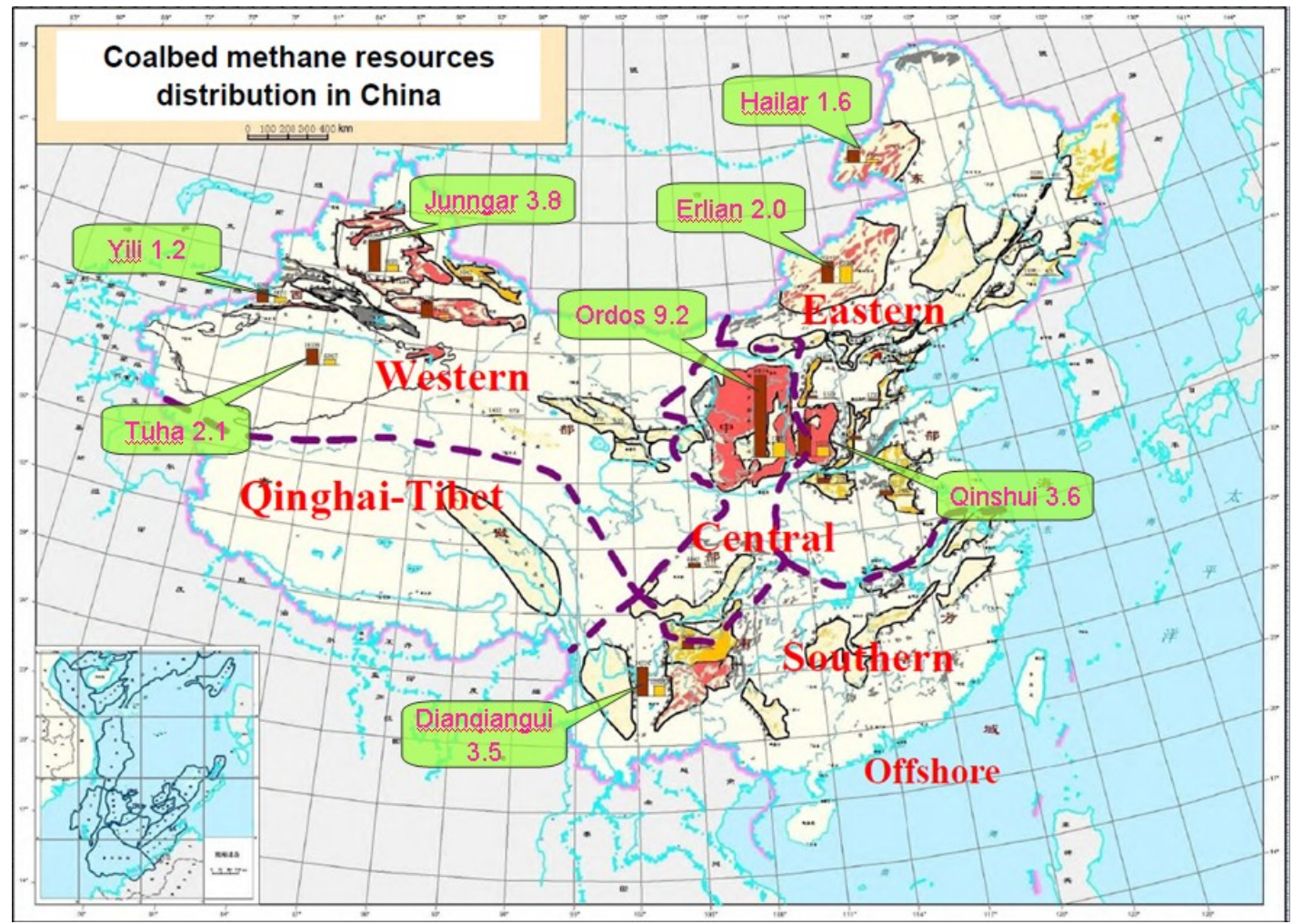

Source: CNPC presentation at the Ninth Sino-US Oil and Gas Industry Forum, 2010

There have been three stages of CBM development in China. Prior to the late 1980s, although there had been no surface CBM development, there had been production in a few coal mines for safety reasons. The success of CBM in Australia and the U.S. was a major inspiration for Chinese producers and policy makers who recognised the significance of CBM and started to make efforts to ensure integrated operations to best utilise both coal and methane in resourcerich basins.

The period 1990-2005 marks the second stage when resource evaluation, exploration and well testing were carried out in various basins. Incentive policies, regulations and the legal framework gradually started to take shape during this period as well. A monopoly company, China United Coalbed Methane Co. (CUCBM), was established in 1996 by the then Ministry of Coal Industry, followed by the Ministry of Geology and Mineral Resources and CNPC to explore, develop and produce methane from coal seams. ${ }^{12}$ After a decade, the company finally saw the first commercial gas flow from its Panhe Block located in Qinshui Basin, North China's Shanxi Province.

\footnotetext{
${ }^{11}$ China National Petroleum Assessment (2003-2007) conducted by the Ministry of Land and Resources.

${ }^{12}$ Coal Mine Methane (CMM) and Coal Bed Methane (CBM) are both methane found in coal seams. The difference is that $\mathrm{CMM}$ is found within mining areas and would be released through mining activities, while $\mathrm{CBM}$ refers to methane in coal seams that would otherwise not be mined. CMM is mostly produced from underground mines during coal production, while CBM is extracted from subsurface using drilling operations which are more similar to oil and gas production.
} 
Beginning in 2006, CBM development entered a third phase with increasing enthusiasm and attention from major oil companies, attracted by the huge resource potential and possible high returns. CNPC withdrew from its joint venture with China Coal in CUCBM and founded its own subsidiary company PetroChina Coal Bed Methane Ltd. in September 2009. Even starting late, CNPC managed to catch up and even exceed its competitors, drawing on its unchallengeable position in upstream oil and gas and a strong balance sheet.

At a glance, China seemed to have ticked all the boxes for CBM to take off in a short period of time: large resource base, preferential policies, accessible facilities and services and foreign technology support; central government had high expectations. The 11th Five-Year Plan for Development and Utilisation of Coalbed Methane (Coal Mine Methane) ${ }^{13}$ announced by the National Energy Administration under the National Development and Reform Commission in 2006, had the ambition of increasing CBM(CMM) national output to 10 $\mathrm{Bcm} / \mathrm{y}$ by 2010 . Half of that production was expected to come from surface exploitation with $100 \%$ utilisation, and the other half from underground (CMM) with over $60 \%$ utilisation. Despite the undeniable strategic significance of CBM, the enormous enthusiasm of policy makers faced a tough reality check. Production remained negligible for almost a decade (1996-2005) with most producers either losing money or barely breaking even. By 2009, it became clear that China would fail to meet its CBM targets set by central government. NDRC's data shows that China produced $8.6 \mathrm{Bcm}$ of methane from coal seams in 2010, of which, only $1.5 \mathrm{Bcm}$ was CBM produced from subsurface wells, far below the target of 5 $\mathrm{Bcm}$. Of all the methane produced from coal seams, less than $40 \%(3.4 \mathrm{Bcm})$ was commercialised, half of the $80 \%$ target set by policy makers. ${ }^{14}$

Naturally, people ask why CBM has so far failed in China. There is no straightforward answer to that question. But in general the failure was due to the underestimation of the immaturity of the industry, and the challenges facing producers. China has since recognised that foreign expertise needs to be adjusted to apply to local conditions before the country can significantly increase the scale of CBM production. Section 2.2 below looks at the key obstacles that prevented the commercialisation of CBM over the past decade. Although there are reasons specific to $\mathrm{CBM}$, there are also many similarities between $\mathrm{CBM}$ and shale gas as they are both unconventional sources of gas. Examining these challenges not only helps identify the areas of improvement for future CBM development, but also has significant implications for the even less mature shale gas sector which has greater production potential.

\subsection{What Went Wrong for CBM in China?}

China has been trying to stimulate CBM production for more than 15 years. Yet despite high expectation from the policy makers, production failed to meet national plan targets. In this section, we try to present what have been the major obstacles to rapid CBM development. Before we go into any details of the reasons, it is relevant to ask whether CBM failed because the targets were too ambitious or the implementation of national plans was poor. We believe both reasons are relevant.

\footnotetext{
${ }^{13}$ NDRC, 2011

${ }^{14}$ Ibid.
} 


\subsubsection{Financing}

Despite enormous interest and enthusiasm in CBM development, the funds the industry received were not proportional to the strategic significance attached to the sector. Lack of financial backing was one of the major obstacles to rapid growth of CBM output.

Central government was extremely supportive of CBM development and, since 1996, created incentives to promote investments in projects. Producers are entitled to a package of financial benefits and policy support, including:

- An initial two-year tax holiday and a 50\% tax reduction for the following three years;

- A subsidy of $0.2 \mathrm{RMB} / \mathrm{cm}^{15}$ (USD 0.0317) from the central government and additional subsidies from local governments;

- Exemption from Value Added Taxes (VAT);

- Exemption from customs duties for equipment and materials imported for CBM projects;

- Priority access to gas pipelines

- Prices agreed between the producer and the buyer rather than regulated by central government.

But although most of these measures undoubtedly had a positive impact, they focused more on the phase of development after the start of commercial production. Direct financial backing from government was seriously lacking at the exploration and appraisal phase where most support was needed while the industry was in its infancy. It is estimated that from the late 1990 s to 2005 , the central government invested only USD 3-4.6 million per year on average on CBM resource exploitation and evaluation ${ }^{16}$. With limited financing from central government, a heavy burden therefore fell on industry players.

Until 2006, CUCBM was the dominant player in upstream CBM business in China. For over a decade, CUCBM's business represented the overall development of the CBM industry. As of 2008, CUCBM had invested 4.8 billion RMB (USD 0.74 billion) in the 13 years since its creation while in comparison, the United States spent over USD \$6 billion on CBM during its formative years, $1983-1995 .{ }^{17}$ Its annual CBM output increased from neglectable in 1983 to $27 \mathrm{Bcm}$ in $1995 .{ }^{18}$ Chinese experts calculate that it takes a minimum of RMB 3 billion to produce $1 \mathrm{Bcm}$ of CBM (USD 4.35/Mcf), excluding exploration and development costs prior to the production phase and transportation of gas to market. ${ }^{19}$ The funds available to CUCBM were completely insufficient to ensure substantial increases in production at the level of the plan targets.

\footnotetext{
${ }^{15}$ The RMB (Renminbi) is the official currency of the Republic of China. An exchange rate of USD 0.1585 to the RNB March 5 2012) is used here.

${ }^{16}$ Sun. Energy, December2009.

${ }^{17} \mathrm{Ibid}$.

${ }^{18}$ Source: data released by EIA in their website..

${ }^{19}$ Sun, 2009.
} 
Table 2: CUCBM's Foreign Partners for CBM projects. ${ }^{20}$

\begin{tabular}{|c|c|c|c|c|c|c|c|}
\hline \multirow[b]{2}{*}{ Signing } & \multirow[b]{2}{*}{ Block } & \multirow[b]{2}{*}{ Province } & \multirow[b]{2}{*}{ Basin } & \multirow[b]{2}{*}{ Foreign Investors } & \multirow{2}{*}{$\begin{array}{l}\text { Chinese } \\
\text { partner }\end{array}$} & \multirow{2}{*}{$\begin{array}{l}\text { Area } \\
(\mathrm{km} 2)\end{array}$} & \multirow[b]{2}{*}{ Reserves } \\
\hline & & & & & & & \\
\hline Jun-98 & Sanjiaobei & Shanxi & Ordos & Sino Gas \& Energy* (49\%) & CUCBM $(51 \%)$ & 1126 & 13 \\
\hline Jun-98 & Haibei & Anhui & Anhui & CVX & CUCBM & $\mathrm{N} / \mathrm{A}$ & N/A \\
\hline Jun-98 & Sanjiao & Shanxi & Ordos & Orion Energy $(70 \%)$ & PetroChina & 448 & N/A \\
\hline Jun-98 & Linxing & Shanxi & Ordos & Sino Gas \& Energy $(65 \%)$ & PetroChina (35\%) & 2616 & 48 \\
\hline Jan-03 & Panxie East & Anhui & Anhui & Green Dragon Gas (60\%) & CUCBM $(40 \%)$ & 584 & 20 \\
\hline Jan-03 & Shizhuang South & Shanxi & Ordos & Green Dragon Gas (60\%) & CUCBM $(40 \%)$ & 455 & 90 \\
\hline Jan-03 & Shizhuang North & Shanxi & Ordos & Green Dragon Gas $(60 \%)$ & CUCBM $(40 \%)$ & 375 & 75 \\
\hline Mar-03 & Qinyuan & Shanxi & Ordos & Green Dragon Gas $(60 \%)$ & PetroChina (40\%) & 3665 & 550 \\
\hline Sep-05 & Baotian-Qingshan & Guizhou & Guizhou & Green Dragon Gas (51\%) & PetroChina (49\%) & 947 & 160 \\
\hline Nov-99 & Liulin & Shanxi & Ordos & $\begin{array}{l}\text { Fortune Oil* }(27.5 \%), \\
\text { Dart Energy }(22.5 \%)\end{array}$ & CUCBM (50\%) & 183 & N/A \\
\hline Aug-99 & Fengcheng & Jinagxi & Jianghan & Green Dragon Gas (49\%) & CUCBM (51\%) & 1541 & 37 \\
\hline May-10 & Dajing & Xinjiang & Junggar & Dart Energy* (49\%) & PetroChina (51\%) & 3696 & N/A \\
\hline Jul-02 & Qinnan & Shanxi & Qinshui & $\begin{array}{l}\text { Far East Energy (66.5\%), } \\
\text { ConocoPhillips(3.5\%) }\end{array}$ & CUCBM & 4,28 & N/A \\
\hline Aug-02 & Shouyang & Shanxi & Qinshui & $\begin{array}{l}\text { Far East Energy (66.5\%), } \\
\text { ConocoPhillips }\end{array}$ & CUCBM & N/A & N/A \\
\hline Dec-02 & Enhong\& Laochang & Yunan & Qinshui & Far East Energy $(60 \%)$ & CUCBM $(40 \%)$ & 1072 & 140 \\
\hline Mar-03 & Jincheng & Shanxi & Qinshui & Telco Energy & CUCBM & $\mathrm{N} / \mathrm{A}$ & N/A \\
\hline Jul-04 & Panzhuang & Shanxi & Qinshui & Asian American Gas & CUCBM & 157 & 20 \\
\hline Mar-07 & Mabi & Shanxi & Qinshui & Asian American Gas & PetroChina & 1381 & 240 \\
\hline Mar-07 & Hancheng & Shanxi & Ordos & Longmen Huifeng Investment & PetroChina & 461 & 405 \\
\hline Apr-08 & Zijinshan & Shanxi & Ordos & Pacific Asia Petroleum & PetroChina & 708 & 109 \\
\hline Jun-08 & Sanjiao & Shanxi & Ordos & Orion Energy $(70 \%)$ & PetroChina & $\mathrm{N} / \mathrm{A}$ & $\mathrm{N} / \mathrm{A}$ \\
\hline Feb-06 & Shilounan & Shanxi & Ordos & Reflection Oil \& Gas Partners & PetroChina & 1011 & 189 \\
\hline Nov-05 & Shiloubei & Shanxi & Ordos & Shell, Verona Development & PetroChina & 2591 & $\mathrm{n} / \mathrm{d}$ \\
\hline Mar-06 & Suzhou & Xinjiang & Junggar & Ivana Ventures $(65 \%)$ & $\operatorname{CUCBM}(35 \%)$ & 856 & 120 \\
\hline Dec-05 & Liuhuanggou & Xinjiang & Junggar & Terra West Energy & PetroChina & 856 & N/A \\
\hline
\end{tabular}

Source: CUCBM \& news reports

CUCBM witnessed a few major changes of ownership as a result of the restructuring of government organisations under the State Council. It ended up in 2003 as a joint venture coinvested by CNPC and China Coal on a 50-50 basis. This structure was intentionally designed to grant the two companies an equal say in decision-making, but turned out to be problematic; neither managed CUCBM effectively as the two companies had different priorities. CBM extraction is more similar to oil and gas production than to coal mining. China Coal, constrained by the size and nature of its core business, did not rank CBM projects high on its investment agenda as the company is not used to large upfront investments involving, high risks with long term returns. The other investor, CNPC, although financially and technically more competent, was preoccupied with upstream operations elsewhere, and was unconvinced that committing human resources and investments to CUCBM was the most efficient way to maximise returns.

\footnotetext{
${ }^{20}$ After the spinoff from CUCBM in 2008, PetroChina took about half of the operating CBM blocks away from CUCBM.
} 
CUCBM has exclusive rights to foreign co-operation to help the company overcome domestic capital constraints. $25 \mathrm{CBM}$ blocks in China were opened to 15 foreign investors with expertise in CBM exploration and production. Most of the opportunities were captured by small companies specialised in CBM development. ${ }^{21}$ Licenses were signed under conditions similar to upstream oil and gas production sharing contracts. Foreign investors hold equity stakes for normally 30 years which comprise three phases: exploration, development and production. Exploration is mostly funded by foreign partners and is recovered when commercial production starts.

The international CBM producers, listed in Table 2, have played an important role in developing CBM projects, not only as financial investors, but also as industry experts which have brought cutting-edge technologies and superb project management skills to China. However, the scale of investments has been constrained by both the size and financial capacity of these companies (most are small cap independents) and/or by the size of blocks that have been licensed to them. Low regulated gas prices provide little incentive for them to commit both capital and human resources to these projects.

\subsubsection{Insufficient Pipeline Infrastructure}

As discussed earlier, it was not until 2006 that China began to see significant increases in natural gas consumption. Lack of infrastructure has been one of the major obstacles to growth. Gas fields are not located in proximity to gas consuming cities along the prosperous coastal areas. Long-distance pipeline transport remains the most secure, stable and costefficient way of delivering gas from inland gas fields to major markets. The Chinese government has been promoting the construction of natural gas infrastructure and improving connections between regional networks since the early 1990s. However, gas pipeline construction fell far behind the pace of demand growth. As of 2010, the total length of China's pipeline network - approximately 50,000 kilometres - accounts for only one tenth of that of the United States, while large diameter trunk lines only account for 15,000 kilometres. Insufficient gas transmission has significantly constrained domestic production.

Large-scale CBM development also requires sufficient market access. Pipeline infrastructure is even more problematic for CBM than for conventional natural gas. As CBM has the same gas composition as conventional natural gas after processing, in theory it can be connected to existing gas pipelines. Actually, most current CBM activities are concentrated in North China's Ordos and Qinshui Basins, where conventional oil and gas activities have been taking place for decades and there is pipeline infrastructure. Most of these pipelines are built and operated by the dominant gas player CNPC. Under monopolistic conditions CBM producers often find it difficult to conclude off-take agreements with the pipeline operator. Due to fast growing demand for natural gas, the majority of pipelines in China are operating close to full capacity and there is little space left for natural gas produced from unconventional reservoirs. Even if there is spare capacity in large diameter trunk lines, CNPC would prioritise its own conventional gas production from neighbouring blocks rather than $\mathrm{CBM}$ production which is small and unstable because of variable wellhead pressure.

\footnotetext{
${ }^{21}$ A few majors, such as Shell and ConocoPhilips, are also involved in a limited way in the CBM business in China.
} 
Even if access is granted, CNPC's monopoly pipeline position places it in a strong bargaining position against other upstream gas producers. A pipeline tariff of approximately RMB $0.80 / \mathrm{m}^{3}$ set by the NDRC means that transportation of CBM through long distance pipelines is economically challenging. The quality of gas from CBM wells is often poorer than that from conventional gas wells. Therefore the gas produced has to be processed (to remove impurities) before it can be accepted into the gas network; processing further adds to costs. In addition, CBM producers have to deal with the pipeline pressure differentials. CBM wells produce gas at lower pressure than conventional gas wells therefore the methane has to be compressed for delivery to high pressure pipelines. For these reasons, CBM by its nature is more costly at the well-head than conventional gas. Additional compression costs further reduce an already narrow profit margin.

Currently, small local CBM companies are adopting a vertically integrated approach to deliver CBM directly to end users. This may be a temporary solution for an industry in its early stages, but is not sustainable for large scale CBM development. Transportation bottlenecks are the principal obstacle to large scale CBM production and utilisation in China. Unless obstacles to market access are reduced and the cost is more certain, we cannot expect CBM producers to significantly boost output.

Building new CBM pipelines, although it is not a commercially attractive option, provides one solution. But that would be very capital intensive. In addition, land access to construct pipelines requires multiple approvals from local government bureaux and given the relatively small volumes produced from CBM wells, it is unlikely that new regional infrastructure can be financed by producers. By the end of 2009, the total length of the dedicated CBM pipeline network was less than $50 \mathrm{~km}$.

\subsection{The Next 5-10 Years}

We expect CBM production to grow steadily over the next 5-10 years. There is strong evidence that the government continues to aim high for CBM development and put in place favourable policies to channel more investments into the sector and remove obstacles preventing large-scale development. Research by Bernstein estimates that with subsidies and tax exemptions, CBM projects deliver returns over $30 \%$ a wellhead price of USD 6-7/Mcf, which makes it competitive against LNG imports at prices close to 12 USD 12/Mcf. ${ }^{22}$

However, the existing market structure will be fundamentally changed. Although there is space for the independents and private investors, Chinese NOCs, especially upstream giant CNPC, will be leading underground production of CBM. This is largely determined by the level of intensity, competition and service sector developments. CNPC not only controls midstream access through its pipeline monopoly, but also holds the vast majority of CBM acreage registered under the MLR. As Table 3 demonstrates, as of 2009 CNPC had registered CBM mining rights for areas covering $161,000 \mathrm{~km}^{2}$, accounting for over $75 \%$ of total CBM acreage. It is unlikely that small cap companies will be able to challenge such dominance.

\footnotetext{
${ }^{22}$ Bernstein Research, December 2010.
} 
Table 3: Registered CBM Acreage in China (as of 2009)

\begin{tabular}{|c|c|c|c|c|c|}
\hline \multicolumn{2}{|r|}{ Company } & \multicolumn{2}{|c|}{$\begin{array}{c}\text { Area } \\
\left(10^{4} \mathrm{~km}^{2}\right)\end{array}$} & \multicolumn{2}{|c|}{$\begin{array}{c}\text { Resources } \\
(\mathrm{Tcm})\end{array}$} \\
\hline \multirow{3}{*}{$\begin{array}{c}\text { PetroChina } \\
\text { CNPC }\end{array}$} & Equity adjustment & 2.1 & \multirow{3}{*}{16.1} & \multirow{3}{*}{\multicolumn{2}{|c|}{16.48}} \\
\hline & $\begin{array}{l}\text { CBM mining rights } \\
\text { blocks }\end{array}$ & 0.3 & & & \\
\hline & $\begin{array}{l}\text { Overlapping area within } \\
\text { oil and gas license blocks }\end{array}$ & 13.7 & & & \\
\hline & CUCBM & 1.76 & \multirow{3}{*}{5.17} & 1.8 & \multirow{3}{*}{7.2} \\
\hline & SINOPEC & 1.62 & & 2.4 & \\
\hline \multicolumn{2}{|c|}{ Other companies } & 1.79 & & 3.0 & \\
\hline & Total & \multicolumn{2}{|c|}{21.27} & \multicolumn{2}{|r|}{23.68} \\
\hline
\end{tabular}

Source: CNPC's presentation at the Ninth Sino-US Oil \& Gas Industry Forum, 2009

However, foreign expertise is still much needed. Although China has the largest number of ongoing CBM projects, single well production remains very low compared with other countries. China has not yet found the most efficient way of replicating the U.S. experience in CBM exploitation and development. It is more important that Chinese NOCs adjust foreign technologies to local conditions, as the geology of coal seams in China is very different from that of the U.S. and Australia. Most of China's coal bearing areas experienced tectonic movements which have resulted in loose and broken coal seams. Coal seams in China often have low permeability and in higher ranks, i.e. are more brittle and faulted, than coals in the prolific basins of the U.S. or Australia. Consequently the effectiveness of drilling and completion techniques used in the U.S. and Australia will be reduced when applied in China. Consequently development tends to take longer and involve higher costs.

Many analyses have emphasised disputes over licensing rights for coal mining and CBM developments as a major reason for the delay and failure of CBM development. While licensing disputes have been and remain a big challenge, there is little evidence that these substantially constrained rapid CBM development over the past decade. The majority of CBM activities in China so far focused on exploration and pilot tests in licensing areas. Although the majors own the vast majority of land from previous licensing rights, the undisputed blocks are large enough to keep each CBM producer busy. For the near future, CBM producers are likely to focus on their own "territories" before expanding to other blocks. However, longer term, conflicts over licences could become a major obstacle to large scale production. This is clearly shown in the new round of license competition between NOCs and small local coal companies. Such competition exposes conflicts of interest between the local and central governments, and also issues related to security and energy production.

Pipeline accessibility will remain a major barrier for 3-5 years, but is expected to be resolved thereafter. Central government has considered breaking CNPC's dominant position in pipeline transmission and allowing third-party access. This has already been achieved in some gas producing provinces where the local governments are keen to integrate regional gas collection and distribution networks with long distance pipelines. Chinese companies have in 
the past proven to be adept and efficient at laying new pipelines. It is therefore expected that once productive capacity is demonstrated, the required infrastructure will be put in place relatively quickly.

As Table 4 shows, the new target outlined in the $12^{\text {th }}$ Five-Year Plan is $16 \mathrm{Bcm} / \mathrm{y}$ by 2015 divided between the major producers: CNPC, Sinopec and CUCBM. The target continues to be ambitious but more realistic than in the $11^{\text {th }}$ Five-Year Plan. The 2020 target $(30 \mathrm{Bcm})$ so far looks reasonable assuming delivery of 2015 targets. But although CBM output will rise rapidly from a relatively low base, the absolute volume will remain modest compared to domestic conventional natural gas production and the soaring demand for gas in China. CBM output is estimated to be around $30 \mathrm{Bcm} / \mathrm{y}$ by $2020^{23}$. Although this volume of gas will be a useful supplementary source of supply, it is unlikely that CBM will significantly change the overall natural gas production outlook.

Table 4: CBM Production Targets Set by the Government and Chinese NOCs

\begin{tabular}{|c|c|c|c|}
\hline & Year & $\begin{array}{l}\text { Production } \\
(\text { bcm/y) }\end{array}$ \\
\hline \multirow{6}{*}{ NOCs } & \multirow{2}{*}{ CNPC } & 2015 & 4.5 \\
\hline & & 2020 & N/A \\
\hline & \multirow{2}{*}{ Sinopec } & 2015 & $2.5^{*}$ \\
\hline & & 2020 & N/A \\
\hline & \multirow{2}{*}{ CUCBM** } & 2015 & 5 \\
\hline & & 2020 & 10 \\
\hline \multirow{2}{*}{\multicolumn{2}{|c|}{ Total }} & 2015 & $10-12$ \\
\hline & & 2020 & $\mathrm{~N} / \mathrm{A}$ \\
\hline \multirow{2}{*}{\multicolumn{2}{|c|}{$\begin{array}{c}\text { NDRC } \\
\text { Five-Year Plan }\end{array}$}} & 2015 & $20-24$ \\
\hline & & 2020 & $\mathrm{~N} / \mathrm{A}$ \\
\hline
\end{tabular}

* Sinopec's target for unconventional gas production in 2015 includes both CBM and shale gas.

** CNOOC acquired a 50\% stake in 2011

Source: news \& company reports

To conclude, production of coal bed methane in China will probably rise steadily over the next decade as the government continues to remove policy obstacles and put in place measures that help promote production. Although there will still be opportunities, the risks involved, both technically and financially for an industry at an early stage of development, are substantial for new small players entering this sector. It is expected that the Chinese NOCs possessing vast resources and strong financial and technological capacity, will defeat the small cap independents in draining CBM from underground. The failure of the past 15 years has created mixed feelings towards foreign co-operation. On one hand, China is keen to narrow the gap between domestic and foreign operators in terms of expertise and technologies. On the other hand, the Chinese government and NOCs are very reluctant to share the valuable resources this energy-hungry country possesses with foreign investors. It is

\footnotetext{
${ }^{23}$ Source: Author's calculation of the production plans released by major CBM producers.
} 
expected that China will be very careful in selecting foreign partners and only the most qualified will be chosen.

In our view, there are many reasons for China's failure to achieve its CBM production targets. Lack of finance, poor quality reservoirs, lack of expertise and skills and conflicts over mineral rights, are all hurdles that have prevented CBM from taking off in a timely manner. But an important reason that often gets ignored is simply the time and amount of work needed to build a new industry from scratch. When policy makers set up ambitious production plans, they concentrated too much on increases in U.S production, but neglected the preparation that was made long before such production levels were achieved. The Chinese government therefore under-estimated the degree of support and effort needed to ramp up CBM production over a short period and set too high a target for too short a period of time before fully realising what it takes to achieve such a goal. Hopefully similar mistakes can be avoided by the country's planners of shale gas developments. 


\section{Shale Gas Development in China: an overview}

Following the boom in unconventional gas production in North America, governments and industry had a significant incentive to replicate the U.S. success story elsewhere in the world. China emerged as a strong candidate given its potentially large unconventional gas resources and soaring demand for natural gas. Domestically, the Chinese authorities and NOCs have been closely observing the dynamics of shale gas developments in the U.S. from regulatory, technical, commercial and environmental perspectives since 2000. Externally, IOCs and international service providers have been actively positioning themselves for early access, assuming commercial developments in the near future.

In this chapter, we will present an overview of China's shale gas development. We start with a brief resource investigation of shale gas potential, followed by an introduction to the current efforts made by both Chinese and international companies. We seek to answer the questions: who are the players; where are their exploration and development activities concentrated; and what are the dynamics between domestic and international companies?

\subsection{Resource Base}

According to an initial assessment of world shale gas resources recently released by the EIA, China possesses abundant shale gas. Of all the 32 countries surveyed worldwide, China ranks highest with 5,100 Tcf $(144.4 \mathrm{Tcm})$ of shale gas in place. Technically recoverable shale gas resources are estimated to be $1,275 \mathrm{Tcf}(36.1 \mathrm{Tcm})$, about $50 \%$ higher than the U.S. (862 Tcf). The two large sedimentary basins - the Sichuan Basin in south-central China and the Tarim Basin in north-west China are believed to be most prospective with favourable reservoir qualities. The EIA also considers other basins with less favourable, but sizeable, non-marine shales: Songliao Basin, Bohai Basin, North China Basin, Ordos Basin, Junggar Basin and Tuha Basin. ${ }^{24}$

\section{Map 3: Major Shale Gas Basins and Pipeline System of China}

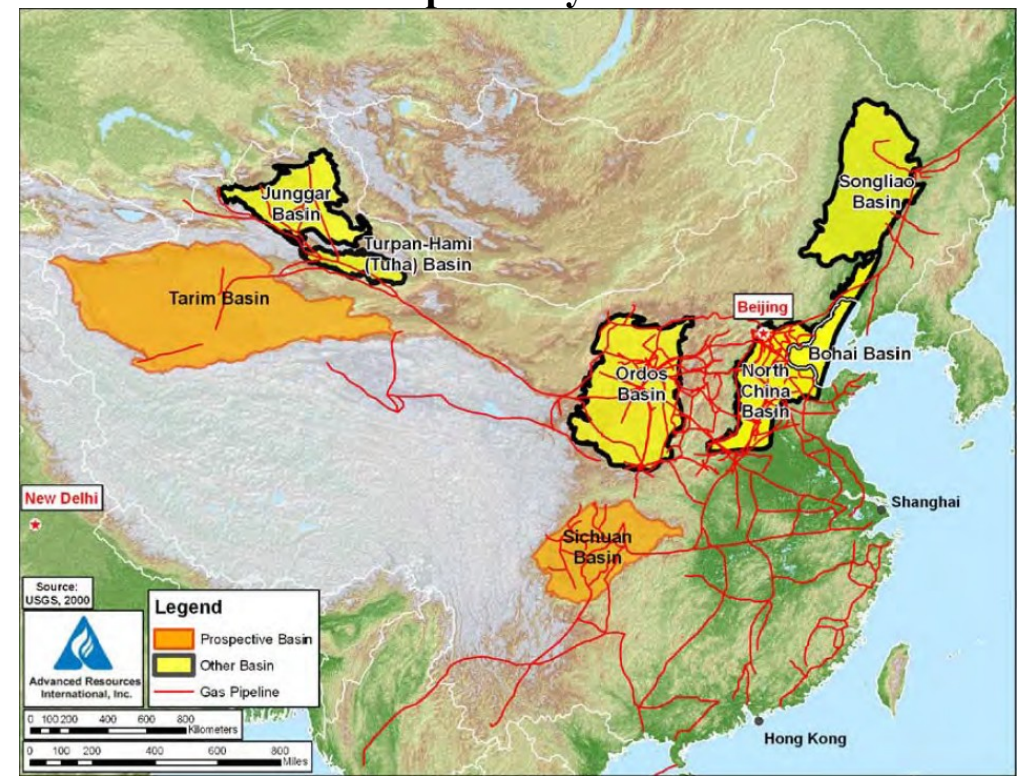

Source: Advanced Resources International Inc, USGS

\footnotetext{
${ }^{24}$ World Shale Gas Resources: An Initial Assessment. April 2011, EIA.
} 
However, resource evaluations conducted by Chinese geologists indicate much more conservative numbers. CNPC's Langfang Research Institute estimates the total volume of natural gas contained in shale formations to be $30.6 \mathrm{Tcm} .{ }^{25}$ Although Chinese geologists disagree with their American colleagues on the scale of the shale resource base, their analysis of the distribution of resources is largely comparable to that of the EIA. CNPC identifies three major marine shale areas, Palaeozoic shale in South China, Lower Palaeozoic shale in North China and Cambrian-Ordovician Shale in the Tarim Basin. Potential shale gas resources in these three main areas reach $21 \mathrm{Tcm}$, accounting for nearly $70 \%$ of the total shale gas in place. In addition, the other five major basins - as shown in Map 4 - are estimated to bear sizeable lacustrine shales. ${ }^{26}$

\section{Map 4: Shale Gas Distribution in China}

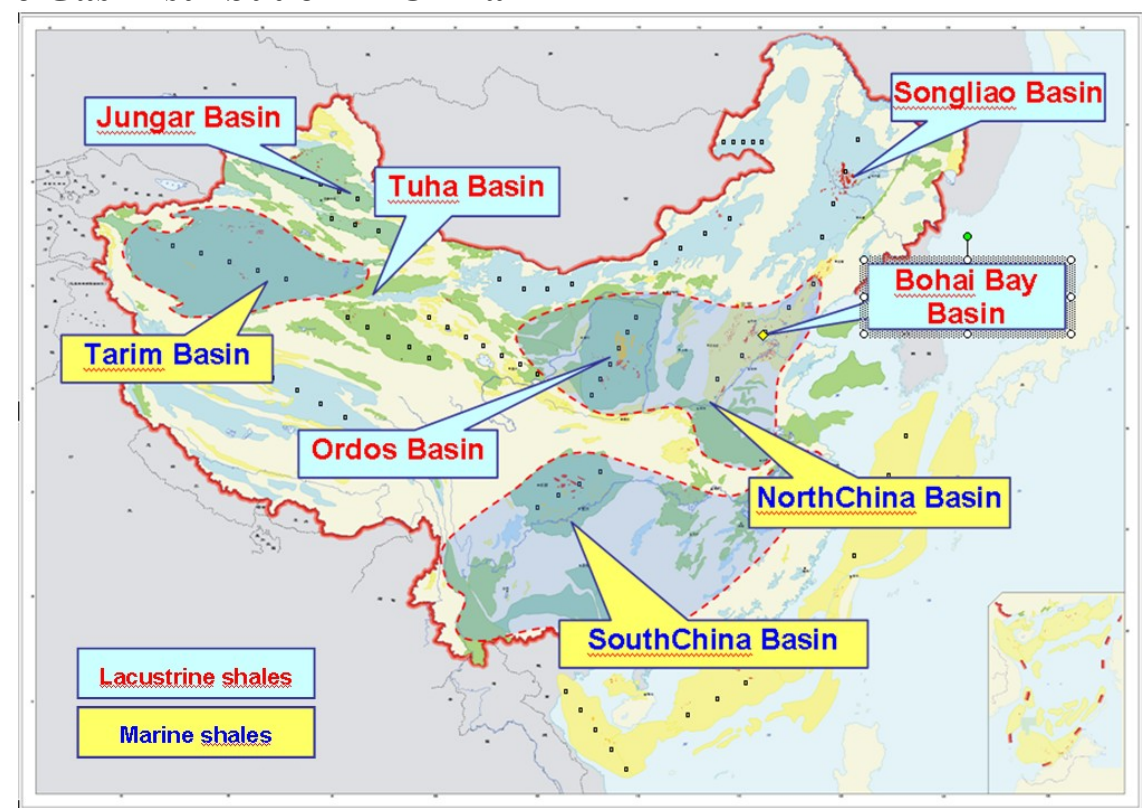

Source: CNPC's Presentation at the 9th Sino-US Oil and Gas Industry Forum

Again, it is important to re-emphasise the early stage of shale gas developments with very limited drilling having been carried out in China. Detailed geological information on shale formations in China is either very limited or not available. Most estimates have been based on analogies to the major shale plays in the U.S., and the above estimates by the EIA, CNPC and others, are highly uncertain. Many countries have just initiated plans to assess their unconventional resource base, and the EIA believes current estimates to be conservative. ${ }^{27}$

\subsection{The Players and Activities}

Developing shale at large scale requires intensive drilling. It is therefore crucial to secure significant acreages in the shale bearing areas. U.S. experience has proven that early access to a large amount of land at low prices greatly helps to ensure profitability. Buying into acreage can be low cost when hard data on the quality of the resource is not available. Once drilling starts and good quality resources are confirmed, the cost of acreage soars. This has been the case for most mature shale bearing basins in the U.S.

\footnotetext{
${ }^{25}$ RIPED Langfang, CNPC, 2009.

${ }^{26}$ RIPED Langfang, CNPC, 2009.

${ }^{27}$ Review of Emerging resources: US Shale Gas and Shale Oil Plays. EIA 2011.
} 
Unlike the speedy land acquisitions for shale drilling in relatively open markets in Europe, China has not yet seen intensive "land grabbing". This is mainly due to the fact that oil and gas exploration and development are strictly regulated. The industry is monopolised by stateown national oil companies (NOCs). The Ministry of Land and Resources registers stateowned oil and gas resources and manages the awarding of assets to NOCs. Most onshore oil and gas E\&P licenses are divided between the two vertically integrated companies - China National Petroleum Corporation (CNPC) and the China Petrochemical Corporation (Sinopec), while the China National offshore Oil Corporation (CNOOC) dominates offshore exploration and production. Foreign investors wishing to participate in China's oil and gas resources must forge partnerships with the major NOCs and obtain approvals from central government.

"Land Grabbing" by foreign companies Small cap energy companies in North America, which were in the front line of shale revolution in the U.S., were among the first movers to seize shale gas opportunities in China. As early as October 2007, Newfield signed an agreement with CNPC to jointly study the shale gas resources in the Weiyuan Block in the Sichuan Basin (southwestern China). This study marked a new era in Chinese co-operation with foreign operators on shale gas developments. Strong interest was registered in 20082009 after major IOCs bought into shale gas assets in North America and tried to penetrate new markets to build on their existing conventional oil and gas positions. The majors, such as ExxonMobil, Shell, BP, Total, Chevron, ConocoPhillips, Statoil and ENI, all expressed interest in China's shale gas resources. As Table 5 shows, many of them managed to conclude joint study/exploration agreements in collaboration with Chinese NOCs.

Table 5: Foreign Players and their Shale Gas Activities in China

\begin{tabular}{|c|c|c|c|c|c|c|}
\hline Date & $\begin{array}{l}\text { International } \\
\text { Companies }\end{array}$ & NOCs & Activity & $\begin{array}{c}\text { Area } \\
(\mathbf{k m} 2)\end{array}$ & Location/Basin & Status \\
\hline Oct 2007 & Newfield & $\mathrm{CNPC}$ & shale gas joint study & $\mathrm{N} / \mathrm{A}$ & $\begin{array}{l}\text { Weiyuan Block, } \\
\text { Sichuan }\end{array}$ & $\begin{array}{l}\text { completed } \\
\text { in } 2008 \\
\end{array}$ \\
\hline Nov 2009 & Shell & CNPC & $\begin{array}{c}\text { shale gas joint } \\
\text { assessment }\end{array}$ & 3,000 & $\begin{array}{c}\text { Fushun-Yuangchuan } \\
\text { Block, Sichuan }\end{array}$ & ongoing \\
\hline Jan 2010 & $\mathrm{BP}$ & Sinopec & $\begin{array}{l}\text { shale gas joint } \\
\text { assessment }\end{array}$ & $\mathrm{N} / \mathrm{A}$ & $\begin{array}{c}\text { Kaili Block, Guizhou; } \\
\text { Huangqiao Block, } \\
\text { Jiangsu }\end{array}$ & ongoing \\
\hline May 2009 & Statoil & CNPC & shale gas joint study & 2,000 & Sichuan & negotiation \\
\hline 3Q 2010 & ConocoPhillips & $\mathrm{CNPC}$ & shale gas & 2,000 & Sichuan & pending \\
\hline 4Q 2010 & Chevron & Sinopec & shale gas exploration & N/A & $\begin{array}{l}\text { Longli County, } \\
\text { Guizhou }\end{array}$ & ongoing \\
\hline 2010 & Shell & CNPC & $\begin{array}{l}\text { tight/shalegas } \\
\text { exploration }\end{array}$ & N/A & Jinqiu Block, Sichuan & ongoing \\
\hline July 2011 & ExxonMobil & Sinopec & shale gas joint study & 3,644 & $\begin{array}{l}\text { Wuzhishan-Meigu } \\
\text { Block, Sichuan }\end{array}$ & ongoing \\
\hline July 2011 & ENI & Sinopec & $\begin{array}{l}\text { MOU covering shale } \\
\text { gas }\end{array}$ & $\mathrm{N} / \mathrm{A}$ & $\mathrm{N} / \mathrm{A}$ & $\mathrm{N} / \mathrm{A}$ \\
\hline
\end{tabular}

Source: CNPC/Press Report

Despite their expertise and considerable experience in developing shale gas, U.S. independents found themselves not viewed very favourably by their Chinese partners. The reasons were three-fold. First, lack of large scale appraisal of shale resources, selection of prospective blocks, and proven techniques to extract gas from the Chinese shale plays. Foreign investors have to start from scratch and have no opportunity to make a quick profit. 
The scale of risks and uncertainties involved are unfavourable for small or medium size independents seeking quick turnover and returns. Secondly, large state-owned enterprises, like the Chinese NOCs, value the strategic significance attached to foreign co-operation. They are keen to get overseas business in return for allowing international competitors into their home territory. The independent U.S. energy companies, although having demonstrable U.S. expertise in unconventional gas exploration, have fewer opportunities to offer to the Chinese NOCs compared with the major IOCs. Thirdly, small or medium sized independents with no footprint in China face higher barriers to entry in a semi-closed market which, in many respects, are substantially different from the business environment they are used to in North America. In contrast, highly integrated IOCs, which have had longer history of foreign cooperation with the Chinese NOCs, see fewer obstacles in overcoming the cultural and operational challenges. Some of these companies, like Shell, BP, and Chevron have already built large businesses and are seeking to expand their presence in China. The size and scale of their business also ensures more influence on their partners and the Chinese authorities than smaller players can expect.

Table 5 shows that the majors have been more successful in securing shale gas opportunities in China than the U.S. independents. It is by no means certain that the companies listed have secured valuable assets. Although no details of these contracts are publicly available, it is believed that most of the agreements so far have been signed under a framework of resource assessment and technology testing, with a low level of commitment for the parties involved. This obviously reflects the uncertainties of an industry in its infancy. But also, foreign participants always risk doing work for their Chinese partners without getting benefits in return. Newfield serves as a good example: its co-operation with CNPC did not go any further than a joint study. For unknown reasons, the two sides decided not to enter the next phase when the study agreement came to an end in 2009. But with assistance from Newfield, CNPC successfully drilled and fractured the very first shale gas well, Wei 201-H1, and obtained commercial gas flows. In contrast, Shell has made greater progress in the FushunYongchuan block in cooperation with CNPC.

The first wave of shale opportunities is nearing its end with companies needing to identify the extent and quality of the resource. Despite ongoing negotiations, we do not expect a large amount of foreign entry into new shale gas opportunities in China - until and unless the Chinese NOCs fail to meet the expectations of the authorities during the first half of the 2010s.

Meanwhile, central government is making national plans to systematically map shale gas resources and create regulations that can help stimulate development. The Chinese authorities have openly said that they have not considered direct foreign investment in shale for the time being, which implies that if their Chinese counterparts succeed in replicating technologies and best practices, the scope for foreign operators will reduce in future. Unless Chinese NOCs fail in their attempts, it is likely that shale gas opportunities for IOCs will dwindle compared with the late 2000 s.

Transferability of the US Business Model: An outstanding feature of shale gas revolution in the United States is the role small and medium sized companies played in the development of shale plays. According to the EIA, $60 \%$ of shale gas developments in the U.S. were carried by independent energy companies. Competition among a large number of independent energy companies has been one of the major factors that has been driving technological 
advancement, and has been responsible for spreading and improving best practices that have played a significant role in bringing down the costs of unconventional gas development.

While observing shale gas development in the U.S., energy policy makers in China have realised that the dominance of the major NOCs will probably slow down the speed at which shale gas is developed. They have been considering embracing U.S. experience, i.e. introducing more competition among domestic oil and gas producers. This historical change naturally evoked significant debate. Although fully acknowledging the necessity of competition for reducing costs and accelerating development, some policy-makers fear repeating the CBM story, in which license holders failed to deliver the resource development at the speed and scale hoped for by government. Therefore, the MLR decided to take a discreet step-by-step approach, striving to make sure the resource would be extracted in a fast and orderly manner.

China held the first auction of shale gas blocks in south-west China on 27 June, 2011. Six companies, including national oil and gas companies PetroChina, Sinopec, CNOOC, CUCBM and provincial companies Shaanxi Yanchang Petroleum and Henan Coal Seam Gas, were invited to place bids to compete for four shale blocks located in China's Guizhou and Chongqing provinces, covering a total area of $11,000 \mathrm{~km}^{2}$. Sinopec and Henan CSG respectively won the Nanchuan block covering an area of $2,197.942 \mathrm{~km}^{2}$ and Xiushan covering 2,038.869 $\mathrm{km}^{2}$. The other two blocks did not receive the minimum number of bids required by law. According to the MLR, winners were chosen based on a comprehensive scoring system covering: development and drilling plans, capital expenditure, technology, equipment and personnel requirements.

\section{Map 5: First Auction of Four Shale gas Blocks in China *}

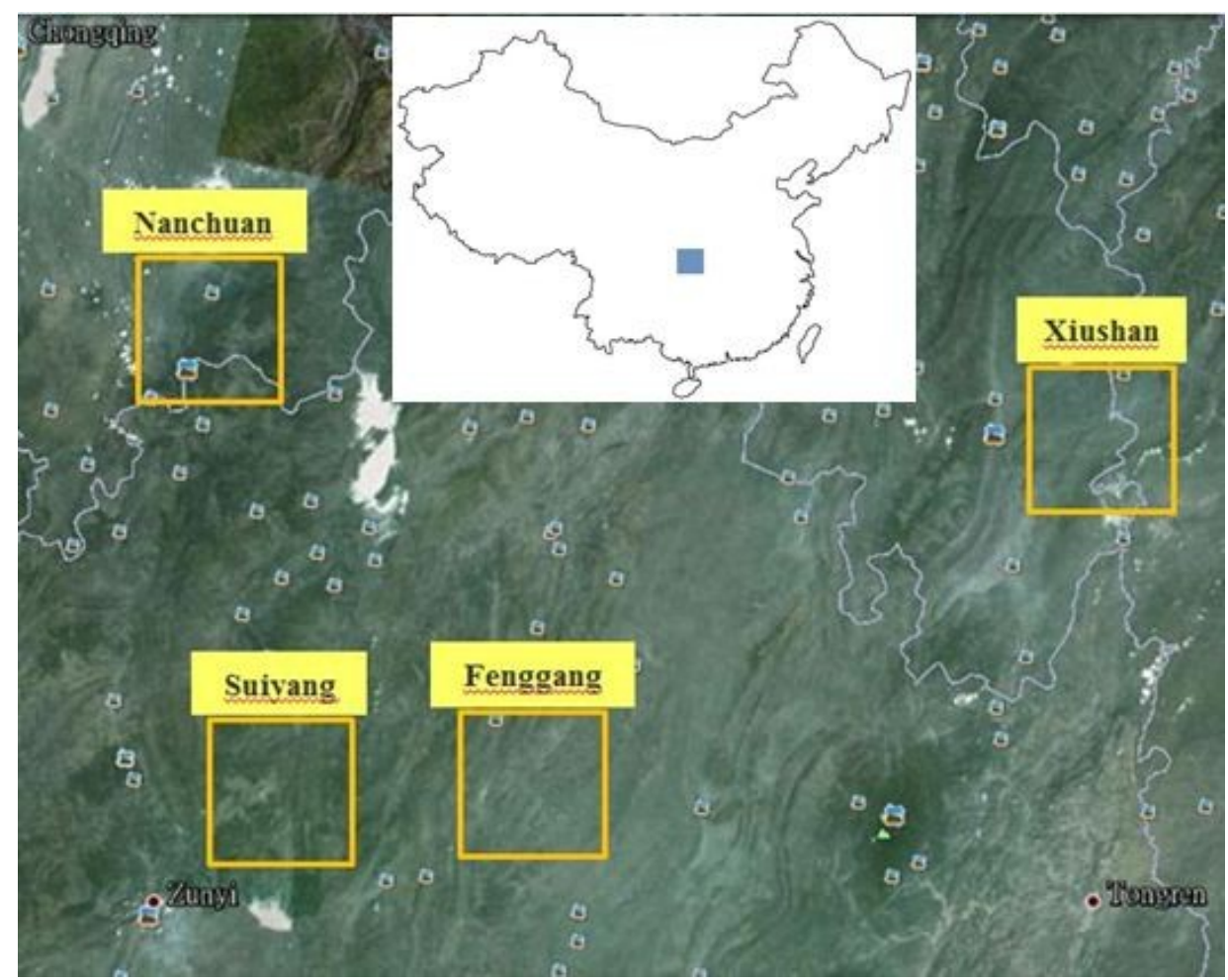

Source: Author (based on the announcement of MLR)

* Icons not in proportion with the size of the blocks 
The first auction was more or less a test run and exposed obstacles that need to be tackled before similar auctions can be repeated. It also had substantial implications for the overall development of shale gas resources in China. Firstly, for the first time in history oil and gas licenses were not awarded based on applications from the three NOCs, but in an open tender involving both national and provincial producers. To a certain extent, the NOCs' monopoly position in exploration and production was broken. The intention was to stimulate internal competition so as to generate the improvements that would benefit the industry and the entire nation.

Secondly, licenses were granted with detailed contractual requirements attached. According to the MLR, the winners are given an exploration period of three years during which minimum capital expenditure of 20,000 RMB per $\mathrm{km}^{2}$ (USD $\$ 12$ per acre) per year is required. The companies must drill at least two wells per $1,000 \mathrm{~km}^{2}$ over the three year period. Spending will be at least 32 million RMB (USD \$5 million) on the Nanchuan block for Sinopec and 122 million RMB (USD \$19 million) on the Xiushan block over the three years. Each has to drill four wells to meet the minimum requirements.

However, it seems that despite strong entusiasm of shale gas advocates from both the industry and government, the MLR has decided to be cautious. The first auction round was in fact semi-closed - only six Chinese companies were invited to bid. It was unclear what criteria were applied in selecting the qualified companies. Some Chinese companies with oil and gas activities overseas but no presence in China, such as Sinochem, Zhenhua Oil, Citic Resources, were excluded from the first auction. The officials of MLR explicitly said that there would be additional auctions involving more shale blocks in the near term, and that the tenders would be open to more companies "with strong financial standing and technology". However, foreign companies will probably continue to be barred from direct involvement.

The number of blocks auctioned in the first round was reduced from the previously reported 6 or 8 blocks to only 4, and the bidding period was postponed a few times to the middle of 2011. In addition, although the MLR was reported to have provided potential bidders with data packages on selected blocks, industry experts suggested the information available was very limited as not a single well had been drilled in those areas. Some suspected that lack of data had caused the failure of the other two blocks to attract sufficient bids. Again, this reflects the immaturity of the shale gas industry. In the autumn of 2011, the MLR announced preparations for the second auction round of shale gas blocks. No doubt additional opening up to foreign investors would help stimulate shale gas development, but their contribution is likely to remain limited, with all blocks to be awarded to Chinese NOCs.

Ultimately the success of China's shale story depends on removing the key obstacles that are likely to prevent quick ramp-up of shale production. These uncertainties will be explained and analysed in more detail in chapter 4. 


\section{Will Shale Gas production in China take off by 2020 ?}

\subsection{Production scenarios}

As discussed in Chapter 1, although China's gas industry started late, domestic production has been growing at more than $10 \%$ per annum for the past decade. Total gas production is expected to reach approximately $150 \mathrm{Bcm} / \mathrm{y}$ by 2015 and $250 \mathrm{Bcm} / \mathrm{y}$ by 2020 . On the demand side consumption has grown at around 20\%/year since 2007 and this will continue due to population and economic growth, environmental protection and decarbonisation. Gas demand is projected to reach $250 \mathrm{Bcm}$ in 2015 and $400 \mathrm{Bcm}$ in $2020 .^{28} \mathrm{As}$ of 2010 , China produced $95 \mathrm{bcm}$ and imported $20 \mathrm{bcm}$ of LNG and pipeline gas. The increasing gap between domestic supply and demand is becoming a concern. Shale gas could emerge as a reliable source of gas supply that could potentially moderate increasing dependence on gas imports.

As the U.S. shale gas revolution evolved, there was a growing expectation from the Chinese authorities that this can be replicated in China. The government announced plans in 2009 to ramp up shale gas production to the level that accounts for $10-15 \%$ of its total gas production by $2020 .{ }^{29}$ In other words, China had a target of producing approximately $20-40 \mathrm{Bcm} / \mathrm{y}$ of shale gas by 2020 . In October 2011, CNPC executives revealed that in the $12^{\text {th }}$ Five Year Plan for shale gas development drafted by the national energy administration under NDRC, policy makers had set a much higher target of producing $50-80 \mathrm{Bcm} / \mathrm{y}$ of shale gas by 2020 . In response to the strong push from the government, gas producers have made production plans. Table 6 summarises the production plans announced so far by major shale players. However, the general impression is that operators seem to be much more cautious than policy makers. The industry has not yet seen ambitious plans for shale production at the level that is comparable to the national plan made by the NEA. The primary reason is lack of quality resource screening and exploration to confirm findings, despite the potentially large overall resource base.

In this section, we construct three scenarios to test whether these goals set by the government are achievable. We also seek to specify what conditions need to be met in order to achieve these goals, and the consequences of such a quick ramp-up on China's energy and gas supply and demand picture. In addition we identify the obstacles which could prevent China from unlocking its shale resources.

Our three scenarios are based on targets set by the government. To simplify our calculations, we have chosen $30 \mathrm{Bcm} / \mathrm{y}$ (half way between 20 and $40 \mathrm{Bcm} / \mathrm{y}$ ), $50 \mathrm{Bcm} / \mathrm{y}$ (the low end of the $12^{\text {th }}$ FYP target) and $80 \mathrm{Bcm} / \mathrm{y}$ (the high end of the $12^{\text {th }}$ FYP target) as the reference production targets in the individual scenarios. We assume China starts drilling and fracturing commercial shale gas wells in 2012 and production begins in January 2013. As shale gas wells have much steeper decline curves $(60-70 \%$ in the first year) than conventional gas wells, we assume drilling and completion reaches its peak in 2019 to achieve maximum annual production in 2020 . That is to say, production of $30 / 50 / 80 \mathrm{Bcm} / \mathrm{y}$ respectively is reached after 8 years of drilling (2012-2019). Again, as a result of the high decline rate, a large number of new wells still need to be drilled every year after 2020 to replace the rapidly diminishing output from existing/old production wells.

\footnotetext{
${ }^{28}$ CNPC Economics and Technology Research Institute, 2010

${ }^{29}$ Zhang, Dawei, MLR, 2009.
} 
Table 6: Shale Gas Production Plans Announced by NOCs and the Government

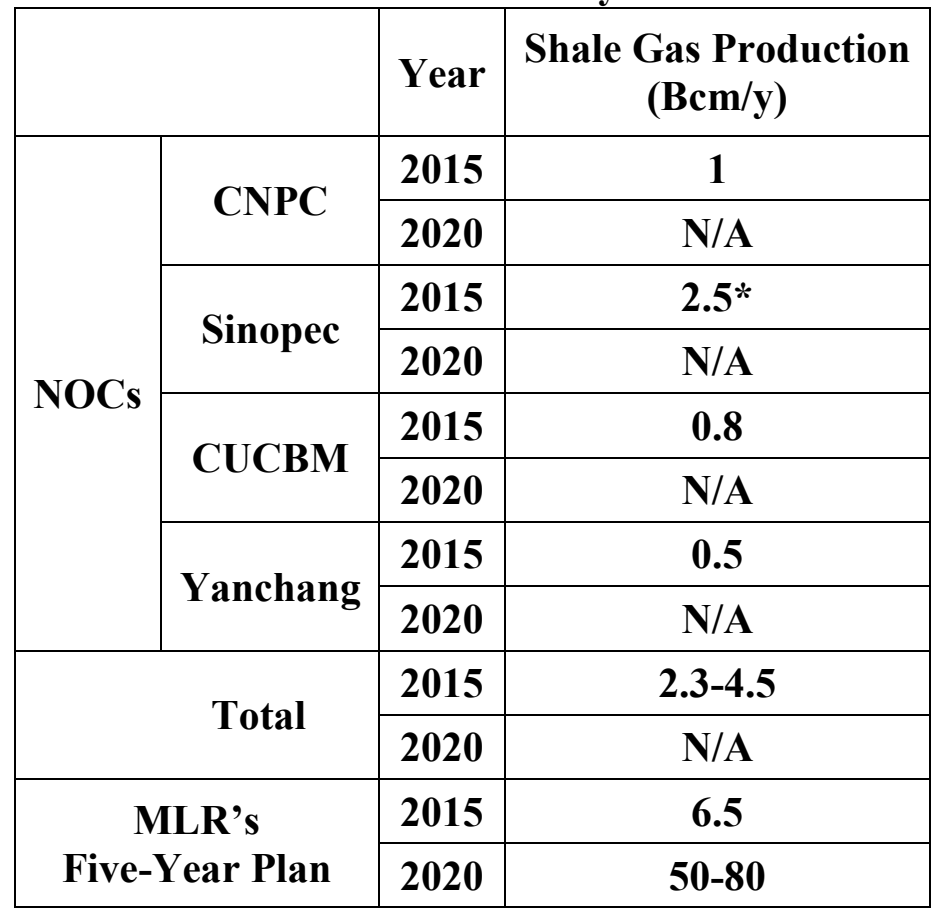

Source: Press releases from early 2010 to 2011

*Sinopec's target includes CBM

Based on the above assumptions the three scenarios are:

- Scenario 1: Shale gas production starts in 2013 and grows steadily from zero to reach $30 \mathrm{Bcm} / \mathrm{y}$ by 2020 , and gradually ramps up to $50 \mathrm{Bcm} / \mathrm{y}$ by 2030 . Shale gas accounts for $10-15 \%$ of China's total gas production during 2020-2030.

- Scenario 2: Shale gas production reaches $50 \mathrm{Bcm} / \mathrm{y}$ by 2020 and sustains that level beyond 2030, accounting for 15-20\% of China's domestic gas production.

- Scenario 3: Shale gas production increases at full speed to reach $80 \mathrm{Bcm} / \mathrm{y}$ by 2020 and sustains that level or even increases over the following decade and beyond. In this case, shale gas accounts for around $30 \%$ of domestic gas production during 2020 2030 .

From a cursory review of the three scenarios, we can draw some preliminary conclusions. In Scenario 1, given the soaring demand for gas during this period (2015-2030), additional gas supply from shale could help relieve China's gas deficit but will not significantly impact production. Scenario 1 therefore has a limited impact on China's gas market.

At a level of $50 \mathrm{Bcm} / \mathrm{y}$ by 2020 (Scenario 2), shale gas accounts for a considerable share of domestic gas production and to a certain extent limits China's increasing dependence on imported gas. However, reaching $50 \mathrm{Bcm} / \mathrm{y}$ by 2020 indicates a steep production curve requiring intensive drilling and fracturing from the beginning of operations. Based on the current status and operational conditions of China's shale gas industry, this would be a very ambitious plan and it must be uncertain whether it is achievable.

In Scenario 3, production of $80 \mathrm{Bcm} / \mathrm{y}$ by 2020 would very significantly increase China's output and the share of gas in total primary energy consumption. However, we believe this 
target is unrealistic. By making an analogue with U.S. shale plays we can get a rough idea of the numbers of wells that need to be drilled in order to ramp up to different production levels. As Figure 3 demonstrates, increasing production from zero in year 2012 to $80 \mathrm{Bcm} / \mathrm{y}$ in year 2020 implies drilling in total over 10,000 wells in 8 years. Considering the natural learning curve of a new industry, we assume a gradual increase of drilling intensity over time; it results in approximately 2,500 wells being drilled in the peak year. Moreover, to maintain the production level for 10 years requires drilling an average of 1,700 new wells every year. Given the immaturity of China's shale gas industry, and the time and energy needed for the major gas producers to build extra capacity, it is simply impossible to accumulate both people and facilities to carry out activities on such a scale before 2020. Insufficient drilling plans announced so far provided by the potential shale producers are also evidence of lack of readiness. Large scale development of shale gas after 2020 remains possible. However, this is difficult to predict as the level of activities beyond 2020 will largely depend on whether or if China will manage to see lights on the horizon after the efforts made in this decade.

\section{Figure 3: Drilling Plan for the 30/50/80 Bcm/y Scenarios}

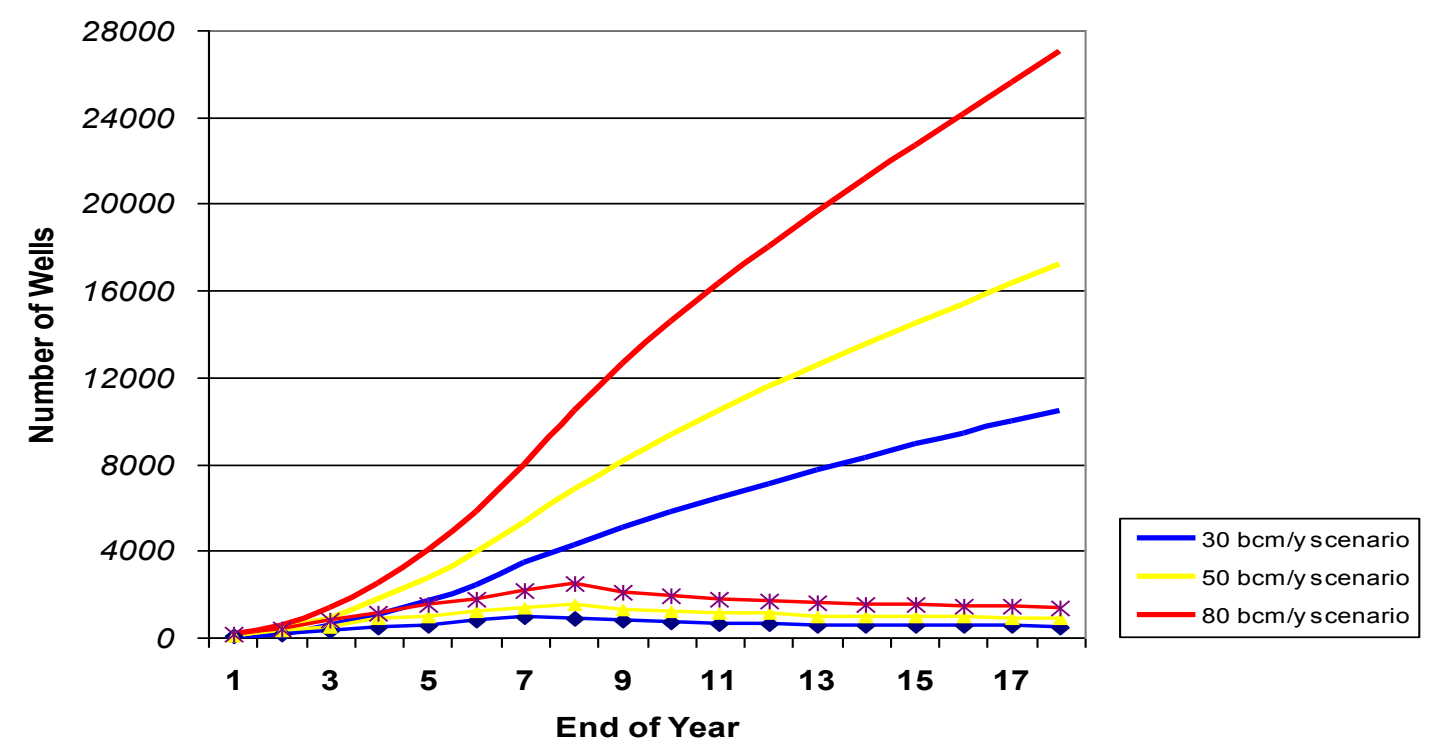

Source: Author's analysis based on World Shale Gas Resources: An Initial Assessment. April 2011, EIA.

Although the three scenarios have not been analysed in great detail, Scenario 2 is, in our view, more critical than the other two. As mentioned above, $30 \mathrm{bcm} / \mathrm{y}$ of shale gas production is relatively small compared with the potential $100 \mathrm{Bcm}$ gap in gas demand and supply in 2020. The $30 \mathrm{Bcm} / \mathrm{y}$ scenario, although still interesting and relevant, is unlikely to have a big impact even in China and still less on global gas balances. Meanwhile, we have concluded that the likelihood of the $80 \mathrm{Bcm} / \mathrm{y}$ scenario is extremely low given the immaturity of the industry. We identify $50 \mathrm{Bcm} / \mathrm{y}$ to be the turning point for shale gas to play a significant role in China's energy sector. We therefore choose to examine the detail of Scenario 2 as it provides an interesting setting to explore the implications of shale gas development. The shale formations analysed so far look similar to the U.S. Barnett and Marcellus shales but are not as promising as the core areas in the U.S. plays. We constructed an analogue of Chinese shale to the Marcellus shale and use the typical Marcellus well production profile to work out a drilling plan that will be needed to make Scenario 2 a reality. 
A typical shale gas well in the Marcellus has an initial production rate (IP Rate) of 3.5 $\mathrm{MMcf} / \mathrm{d}$ and a decline rate of $70-75 \%$ for the first production year. We assume that drilling starts with 100 wells in 2012 and increases rapidly from that date. Figure 4 illustrates the number of wells that need to be drilled annually and cumulatively to produce $50 \mathrm{Bcm} / \mathrm{y}$ within 8 years and maintain this production level for a further 10 years. To maximise production in 2020, drilling activity reaches its peak in 2019 at 1,500 wells per year. In total, around 7,000 wells need to be drilled in 8 years to produce $50 \mathrm{Bcm}$ of gas in 2020. Thereafter in the 2020s, 1,000 new wells need to be drilled annually to sustain this production level. Otherwise, the production curve will drop sharply as a result of the high decline rate.

\section{Figure 4: How to Produce $50 \mathrm{Bcm} / \mathrm{y}$ in 8 Years and Sustain Production for 10 Years}

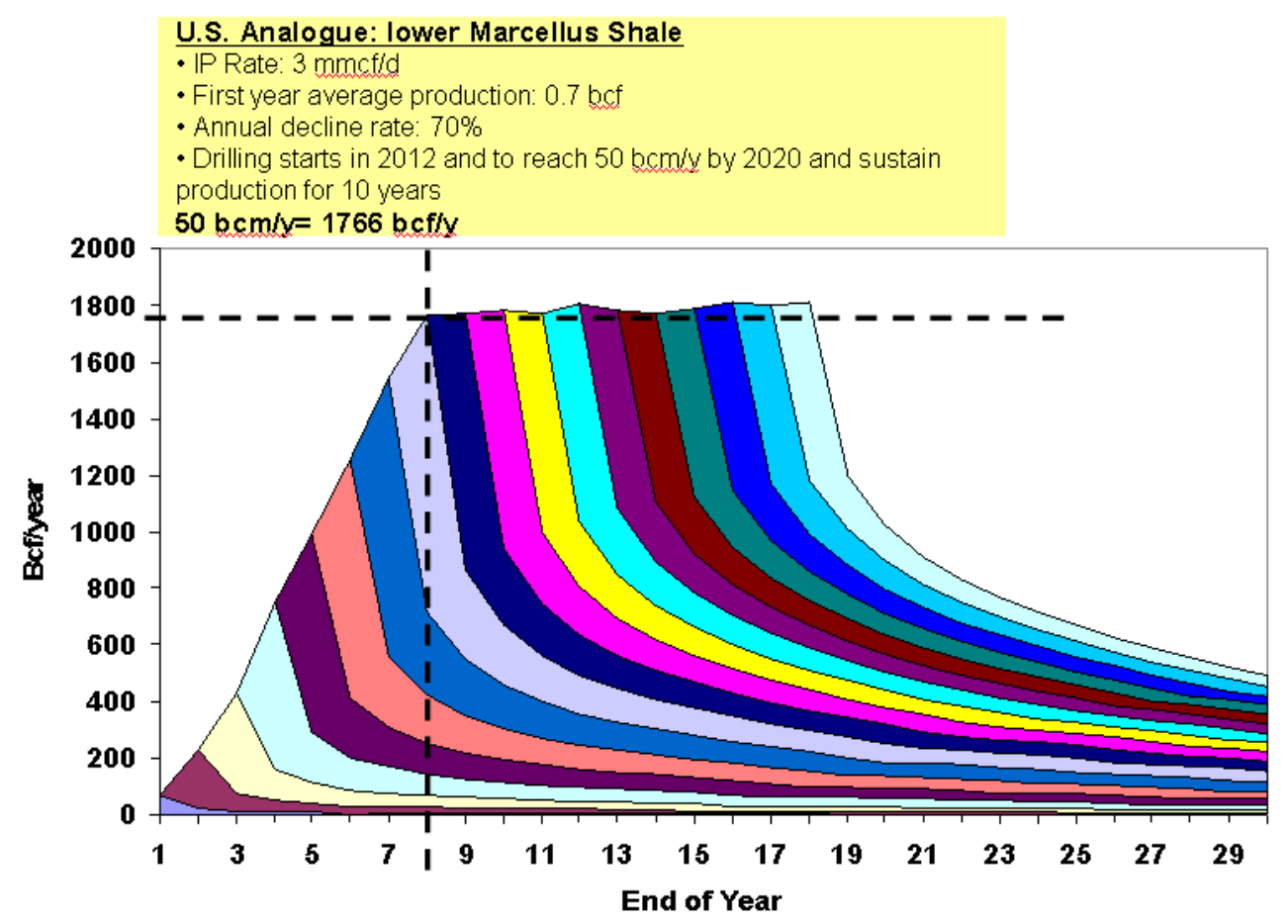

Drilling Plan

\begin{tabular}{|c|c|}
\hline $\begin{array}{c}\text { Year of } \\
\text { drilling }\end{array}$ & $\begin{array}{c}\text { Number of } \\
\text { Wells }\end{array}$ \\
\hline 2012 & 100 \\
\hline 2013 & 300 \\
\hline 2014 & 500 \\
\hline 2015 & 850 \\
\hline 2016 & 1000 \\
\hline 2017 & 1200 \\
\hline 2018 & 1400 \\
\hline 2019 & 1500 \\
\hline 2020 & 1300 \\
\hline 2021 & 1200 \\
\hline 2022 & 1100 \\
\hline 2023 & 1100 \\
\hline 2024 & 1000 \\
\hline 2025 & 950 \\
\hline 2026 & 950 \\
\hline 2027 & 950 \\
\hline 2028 & 900 \\
\hline 2029 & 900 \\
\hline Total & 17200 \\
\hline
\end{tabular}

Source: Chesapeake, Geny, F. ${ }^{30}$

In addition to the number of wells there are other operational requirements that are crucial to the successful implementation of such a drilling plan, including availability of rigs and fracturing equipment, land access and water usage, infrastructure for transporting gas to the market, etc. We examine these requirements in more detail to demonstrate whether such a target is achievable.

\subsection{Operational Requirements}

In this section, we try to detail the operational requirements for large scale shale gas to be developed in China. Such requirements include: land access, water availability, technology and service industry, etc.

\subsubsection{Land Access}

First of all, operators need to obtain mineral rights to explore the subsurface. Similar to conventional oil and gas activities, unconventional drilling can only be conducted in areas

\footnotetext{
${ }^{30}$ Geny, F, 2010.
} 
where the operators hold mineral licenses registered by the MLR. As mentioned previously, preliminary resource screening indicates that shale plays in China largely overlap with conventional oil and gas bearing basins. The MLR have not requested operators to reapply for rights to explore unconventional resources in areas where they currently hold these rights. Although the sweet spots and exact reserve numbers are unknown before a more in-depth and detailed resource assessment is completed, geologists expect that NOCs possess roughly $70 \%$ of China's total shale gas resources in their existing acreages. It is also for this reason that NOCs, and especially CNPC, demonstrated less interest in the new shale gas license rounds initiated by the MLR. They are preoccupied with identified promising areas in their own acreages that are probably among the best in China.

Once operators have legitimate rights to drill, a critical question is whether there would be sufficient access to land that can accommodate such intensive drilling. To get a general idea of the size of acreage that is needed to implement the drilling plan for Scenario 2, we assume a similar well spacing of 80 acre per well $\left(0.3 \mathrm{~km}^{2} /\right.$ well $)$ to that commonly used in the major shale plays in the U.S. As drilling peaks in 2019, the cumulative number of wells needed for raising production to $50 \mathrm{Bcm} / \mathrm{y}$ and maintaining this level for 10 years implies at least 5,100 $\mathrm{km}^{2}$ of land.

This, however, only involves drilling at the development phase when the sweet spots have been identified after exploration. Prior to development, land needs to be obtained for exploration drilling. In addition to the construction of drilling sites, more surface land will be needed to build roads, water pits, and gas processing and transmission infrastructure that are closely related to development and production activities. If we add all these land usages together, the total number can be substantially larger, but still small compared with the vast distribution of source rocks in the country and the mineral rights held by oil and gas producers. For example, geologists estimate that the total explorable area in the Sichuan Basin is $180,000 \mathrm{~km}^{2}$. The dominant acreage holder, CNPC, has 131 mining rights covering an area of $168,700 \mathrm{~km}^{2}$ in the basin. ${ }^{31}$ In theory, CNPC's land area alone is capable of accommodating a level of drilling in Sichuan to achieve the $50 \mathrm{Bcm} / \mathrm{y}$ scenario.

Although general land access is not a huge challenge facing China, the cost and time involved to access the best locations for drilling can be bottlenecks due to topography of the regions, population densities and protection of farm land.

Topography and Population Density: China's topography is varied and complicated. About $33 \%$ of the land is comprised of mountains, $10 \%$ hills, $26 \%$ high plateaux, $19 \%$ basins and only $12 \%$ plains. The characteristics of land and climate led to a concentration of population and economic activity in the flat and fertile plains of Northeast, North and South China. With 1/15 of the world's total land area, China supports 1/5 of the world's population and population density is therefore high. The country's unique topography intensifies the population density problem.

As Map 6 demonstrates, China has one of the highest population densities in the world. Over 1.3 billion people live in the heavily inhabited East, North and South parts of the country. Unfortunately, in the relative water-abundant areas where fresh water is more likely to be available for hydraulic fracturing, land access for drilling can be costly to obtain. The Sichuan Basin is the area where shale gas development is mostly likely to take off. With over

${ }^{31}$ Luguang Li, CNPC. 2011 
70 million inhabitants, Sichuan's population density is around 538 persons $/ \mathrm{km}^{2}$, making it one of the most populated areas in China and in the world. Sichuan is not the only oil and gas bearing basin with a high population density. As Map 4 shows, the South China Basin, North China Basin and Bohaibei Basin all have densities exceeding 250 persons $/ \mathrm{km}^{2}$.

Map 6: Population Density of China and the World. (2000)

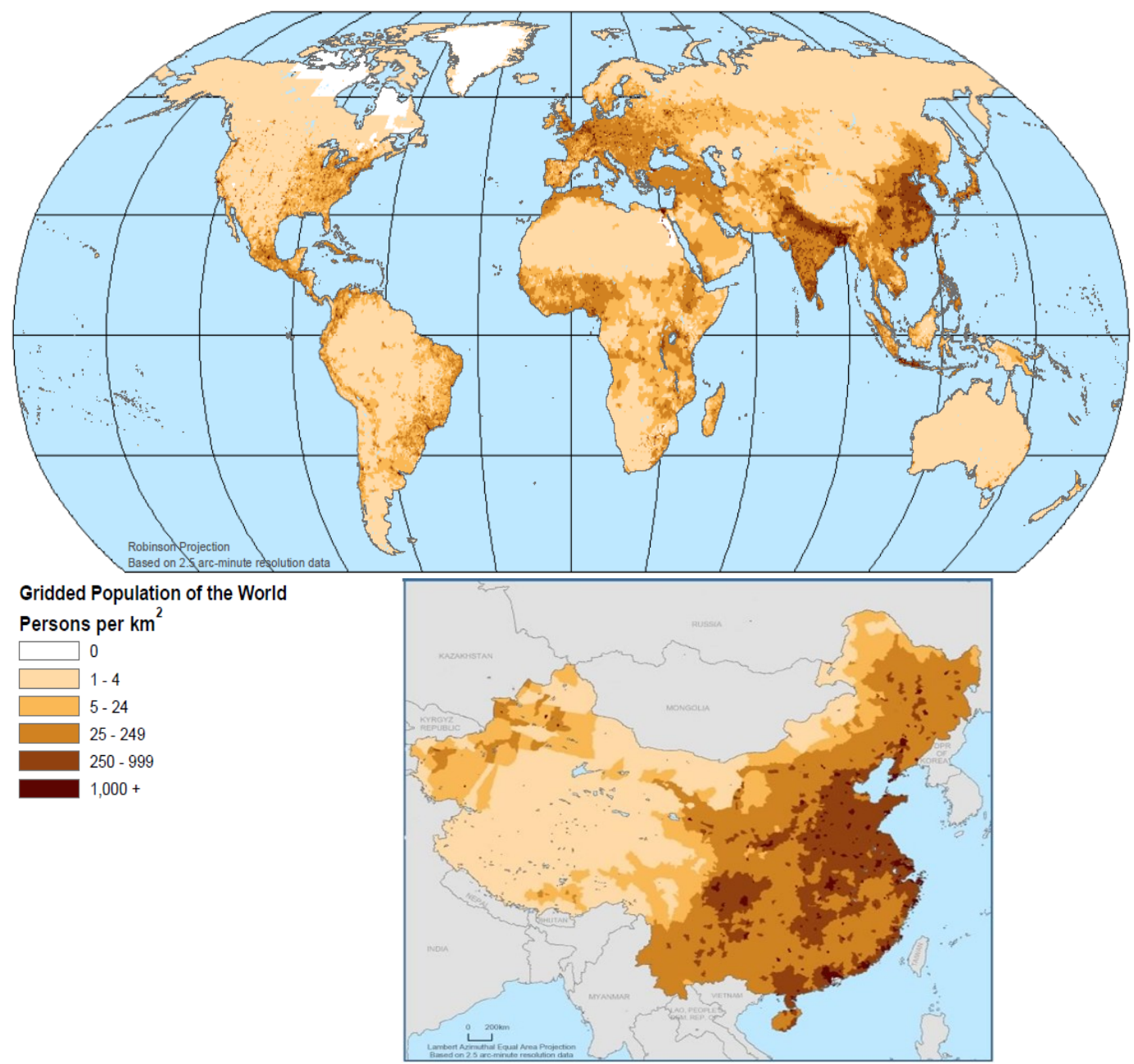

Source: Gridded Population of the World. CIESIN at The Earth Institute of Columbia University. 2001

High population density generally represents a high level of occupation of land with buildings and infrastructure that are essential for sustaining the population. Naturally there would be little flat land available in townships and cities. Although in some parts of North America urban drilling is permitted to unlock resources in gas deposits beneath cities, this may create serious health and security hazards in a country such as China with a much higher population density. Such a high level of population density is not rare, but general across vast areas of China. In addition it indicates the country's lack of ability to relocate people and economic activity to other less densely populated regions, which in North America is possible. 
In relatively remote agricultural areas, flat surface land has long been opened up for farming but despite this, China has only 7\% of the world's farmland, and per capita farmland occupation is only about half of the world average rate. In the last 2-3 decades, remarkable economic success in China has caused rapid loss of farmland for residential, industrial and commercial uses. Farmland preservation is a deep concern for ensuring food security and protecting the fundamental interests of people in underdeveloped areas. This further restricts access to land for large scale shale gas drilling. ${ }^{32}$

Water Challenges: Hydraulic fracturing is essential to produce oil and gas from tight rocks and has been crucial to commercialising the development of shale oil and gas formations in the U.S. Hydraulic fracturing is a stimulation treatment that has been commonly used in lowpermeability shale or tight oil and gas reservoirs. Treatment fluids with additives and proppant are pumped at high pressure into the reservoirs to create fractures that allow oil and gas to flow to the surface. This technique requires a large amount of water and in the U.S. there has been sufficient fresh water for this purpose. It may be possible to use specially treated saline water but this is not yet common practice due to availability and costs.

Data from the major shale gas producing areas in the U.S. suggest that the amount of water needed for fracturing shale deposits is significantly larger than for CBM production. According to the EPA, typical water usage per well is 3-4 million U.S. gallons (11-15 thousand $\mathrm{m}^{3}$ ). (EPA, 2010) The specific water requirements for each shale well depends on the characteristics of the formation (depth, porosity, organic content, etc.) and the design of the fracturing operations (fracturing fluid properties, length of horizontal portion of shale well, number of stages of fracture.) Shale wells with greater depth, higher porosity, longer horizontal sections and more stages of fracture generally require more fresh water. In order to maximise the production potential of wells, the industry has made increasing efforts to drill longer horizontal wells with multi-staged fracturing. In good shale formations, horizontal wells reach over 3000 meters with 40 stages of fracturing. Up to 6 million gallons (23 thousand $\mathrm{m}^{3}$ ) - is needed to drill and fracture a deep shale gas well. ${ }^{33}$ The major sources of water include surface water collected from rivers, streams, creeks, lakes; discharge water from industrial or city wastewater treatment plants; re-use of fracturing water and groundwater from underground aquifers.

In the U.S., intensive drilling and fracturing in the major shale gas producing areas have put pressure on meeting the requirements of local populations for large volumes of fresh water. According to U.S. Environmental Protection Agency estimates, in recent years approximately 35,000 shale wells are drilled and fractured annually across the United States ${ }^{34}$. Assuming 24 million gallons of water for each well, the total annual water usage will reach from 70 to 140 billion gallons ${ }^{35}$. The number is expected to rise as a number of large shale producing areas (e.g. Marcellus, Eagle Ford) are reaching peak shale gas drilling and production periods.

Although society has become increasingly concerned about usage and management of water in the shale gas industry, the availability of water has not yet been an issue in the U.S. given

\footnotetext{
${ }^{32}$ AQUASTAT. FAO's information system on water and agriculture.

${ }^{33}$ For instance, a Chesapeake Energy release in May 2011 said that it took 5.6 million gallons of water to drill and fracture a Marcellus deep shale gas well.

34 EPA, Feb 2011.

${ }^{35}$ EPA, Feb 2011.
} 
its abundant endowment of fresh water resources. However, water shortage can potentially be a big obstacle to shale gas development in China where freshwater resources are far lower than in the US.

Again, we assume similar patterns and volumes of water usage for Chinese shale wells. As discussed previously, shale formations in the Sichuan Basin are located at greater depths than those in the U.S. We therefore quote the high end (4 million gallons per well) of average volumes of freshwater needed for fracturing. Moreover, we assume that a quarter of the water can be recycled and reused for new wells. This reduces the average water usage per well to 3 million gallons. Table 7 shows a drilling and water usage scenario to maintain a production level of $50 \mathrm{Bcm} / \mathrm{y}$ over 10 years. The total net water needed can reach 40.8 billion gallons, equal to 154 million $\mathrm{m}^{3} / \mathrm{y}$. Based on the annual residential usage per capita for the whole of China's 1.3 billion population of $59.5 \mathrm{~m}^{3} /$ capita/year, (derived for 2010 from Table 9), the shale gas water usage figure of 154 million $\mathrm{m}^{3} / \mathrm{y}$ represents that consumed annually by a city of 2.6 million residents. The challenge is how to source this additional volume in a country already struggling to keep pace with growing water consumption.

Table 7: Annual Water Usage for Maintaining $50 \mathrm{Bcm} / \mathrm{y}$ Production over 10 Years

\begin{tabular}{|c|c|c|c|c|}
\hline Year & Wells Drilled & $\begin{array}{c}\text { Water } \\
\text { Usage } \\
\text { (million } \\
\text { gallons) }\end{array}$ & $\begin{array}{c}\text { Water } \\
\text { Recycling } \\
\text { (million } \\
\text { gallons) }\end{array}$ & $\begin{array}{c}\text { Net Water } \\
\text { usage } \\
\text { (million } \\
\text { gallons) }\end{array}$ \\
\hline 1 & 2500 & 10000 & 2500 & 7500 \\
\hline 2 & 1800 & 7200 & 1800 & 5400 \\
\hline 3 & 1500 & 6000 & 1500 & 4500 \\
\hline 4 & 1350 & 5400 & 1350 & 4050 \\
\hline 5 & 1250 & 5000 & 1250 & 3750 \\
\hline 6 & 1150 & 4600 & 1150 & 3450 \\
\hline 7 & 1100 & 4400 & 1100 & 3300 \\
\hline 8 & 1000 & 4000 & 1000 & 3000 \\
\hline 9 & 1000 & 4000 & 1000 & 3000 \\
\hline 10 & 950 & 3800 & 950 & 2850 \\
\hline Total & 13600 & 54400 & 13600 & 40800 \\
\hline
\end{tabular}

Source: Author's analysis

Overview of China's water Resources: China is a nation with severe water scarcity. Aquastat $^{36}$ data show that China's per capita annual renewable water availability is around $2,080 \mathrm{~m}^{3}$, compared with $3,398 \mathrm{~m}^{3}$ for Japan and nearly $10,000 \mathrm{~m}^{3} /$ for the United States. Considering per capita water resources, China is the second lowest in the world, less than one third of the world average.

\footnotetext{
${ }^{36}$ Aquastat is FAO's (Food and Agriculture Organization of the United Nations) global information system on water and agriculture.
} 
Table 8: Per Capita Water Availability (Total Renewable Water Resources) $\left(\mathrm{m}^{3} /\right.$ capita/year $)$

\begin{tabular}{|l|l|}
\hline China & 2,080 \\
\hline Japan & 3,398 \\
\hline United States of America & 9,974 \\
\hline World Average & 6,466 \\
\hline
\end{tabular}

Source: 2009 FAO of the U.N.: Aquastat database, www.fao.org

The U.N. lists China as one of the 13 countries with the most serious water shortages. China has to supply $21 \%$ of the world's population with about $6 \%$ of its fresh water resources. According to the U.N., approximately 300 million people in China have insufficient access to water. More than two-thirds of cities suffer from water shortages and one-sixth are severely affected.

China's water scarcity is reflected in its water footprint. ${ }^{37}$ According to a 2007 study, the Chinese people have a relatively low water footprint with an average of $700 \mathrm{~m}^{3} / \mathrm{cap} / \mathrm{yr}$ compared with India's $987 \mathrm{~m}^{3} / \mathrm{cap} / \mathrm{yr}$ and United States' $2480 \mathrm{~m}^{3} / \mathrm{cap} / \mathrm{yr} .{ }^{38}$ As Map 7 shows, China is in the category of countries with the lowest water footprint. The total volume of water consumption of a country is generally related to its gross national income. Given its fast growing GDP and large scale industrialisation and urbanisation, China's water footprint is exceptionally low.

\section{Map 7: Average National Water Footprint per Capita ( $\left.\mathbf{m}^{3} / \mathrm{capita} / \mathrm{year}\right)$}

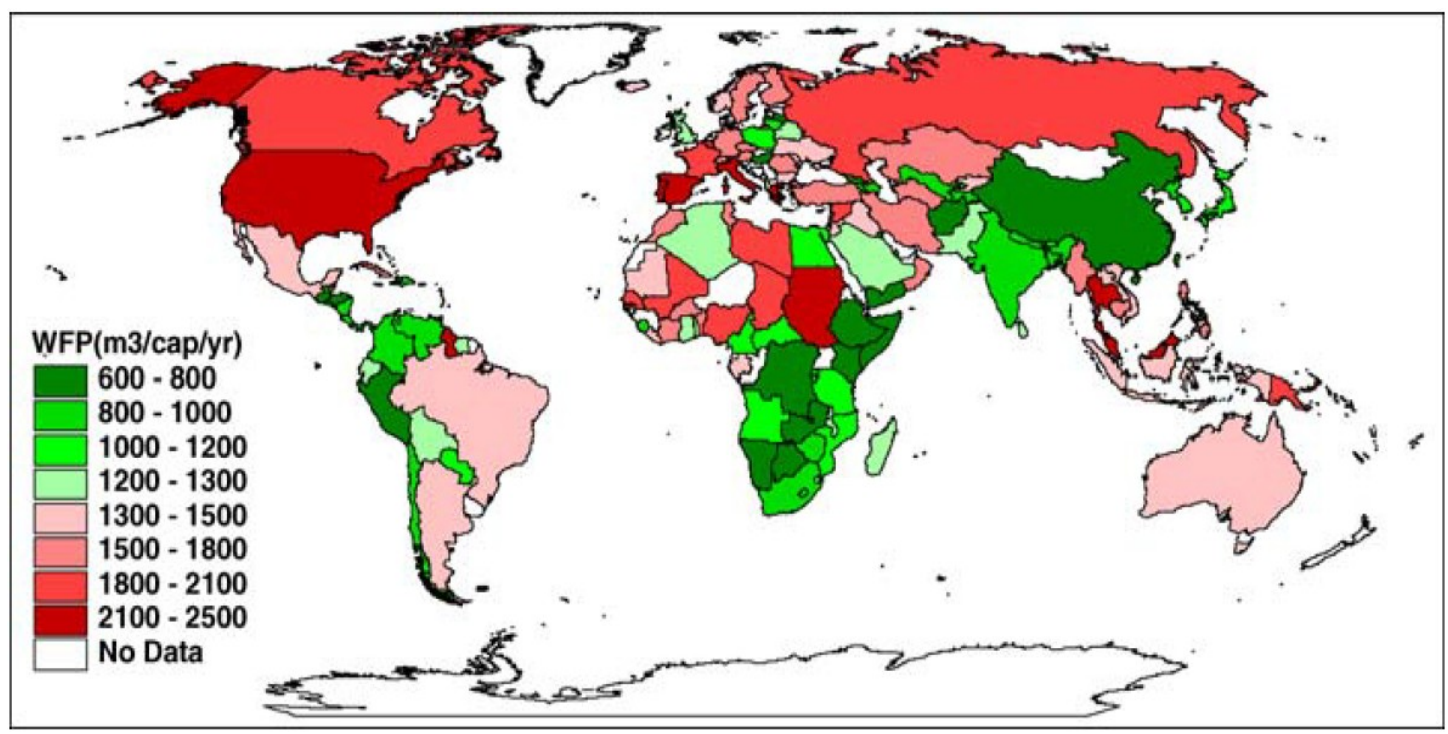

Source: Hoekstra and Chapagain (2006).

\footnotetext{
${ }^{37}$ The water footprint of a country is defined as the total volume of fresh water needed for the production of the goods and services consumed by the inhabitants of the country.

38 Hoekstra and Chapagain, 2006.
} 
The global water footprint on average is $1,240 \mathrm{~m}^{3} / \mathrm{cap} / \mathrm{yr}$. Green indicates that the nation's water footprint is equal to or less than global average. Countries with red have a water footprint higher than the global average.

Table 9 shows water consumption by sector in 2000 and 2010. Although industrial usage has increased by approximately $23 \%$ in the last decade, agriculture remains the largest consumer, using over $60 \%$ of the fresh water in China. As a result of fast population growth and rising living standards, it is expected that residential usage of water will also increase, constraining the resources that could be used by industry. Water shortage has long been a major constraint on economic growth.

Table 9: China's Water Consumption by Sector (2000\&2010)

\begin{tabular}{|c|c|c|c|c|}
\hline & \multicolumn{2}{|c|}{ Year 2000 } & \multicolumn{2}{c|}{ Year 2010 } \\
\hline Sector & $\begin{array}{c}\text { Volume of } \\
\text { Consumption } \\
\left.\text { (billion } \mathrm{m}^{3} / \mathrm{yr}\right)\end{array}$ & Percentage & $\begin{array}{c}\text { Volume of } \\
\text { Consumption } \\
\text { (billion m3/yr) }\end{array}$ & Percentage \\
\hline Agriculture & 348.5 & 62.6 & 370.7 & 61.8 \\
\hline Industry & 114.1 & 20.5 & 140.7 & 23.4 \\
\hline Residents & 60.1 & 10.8 & 77.3 & 12.9 \\
\hline Replenishment & N/A & N/A & 11.1 & 1.9 \\
\hline Total & 556.7 & 100 & 599.8 & 100 \\
\hline
\end{tabular}

Source: The Ministry of Water Resource, $2010^{39}$

Uneven Distribution of China's Freshwater Resources: The distribution of water in China, as in many other countries, is highly uneven between regions and seasons. In summer, the East Asia monsoon brings relatively high precipitation to vast areas of eastern and southern China. However, the mountains and plateaux of northern and western China prevent the monsoon from penetrating into the north-west of the continent, resulting in low precipitation. Landmass and climate are jointly responsible for water resources available to inhabitants, ranging from less than $500 \mathrm{~m}^{3 /}$ person/year in the North to over 25,000 $\mathrm{m}^{3} /$ person/year in the south-west. ${ }^{40}$ Map 8 gives a general indication of the precipitation and distribution of water resources in China. Water shortages are particularly severe on the plains of north China where $40 \%$ of the population have to survive with only one-fifth of the country's fresh water resources. In recent decades, growing population and economic activities led to an increasing deficit of both surface water and groundwater. Overuse and contamination of fresh water is seriously damaging the eco-system and hindering sustainable development. Even the relatively water-rich south China is encountering increasing water shortages.

Unfortunately not only do Chinese shale deposits not always overlap with the most water-rich regions (see Map 4 in chapter 3); but on the contrary, most shale gas bearing basins in China are located in water-scarce locations. The worst areas are the Tarim, Tuha and Junggar basins in the desert areas in north-west China with serious water shortages. The Ordos Basin, Bohaiwan Basin, North China Basin, and Songliao Basin in north and north-east China are in

\footnotetext{
39 "Statistic Bulletin on China Water Activities." Ministry of Water Resources of China, 2010.

${ }^{40}$ Source: FAO, 2010
} 
a relatively better but still difficult position. The Sichuan and South China Basins are the only exceptions, with relatively abundant water resources. This is a serious problem as large volumes of water are essential for the development of shale gas unless there is a major technology breakthrough to significantly reduce water use.

\section{Map 8: Precipitation and Distribution of Water Resources ${ }^{41}$}

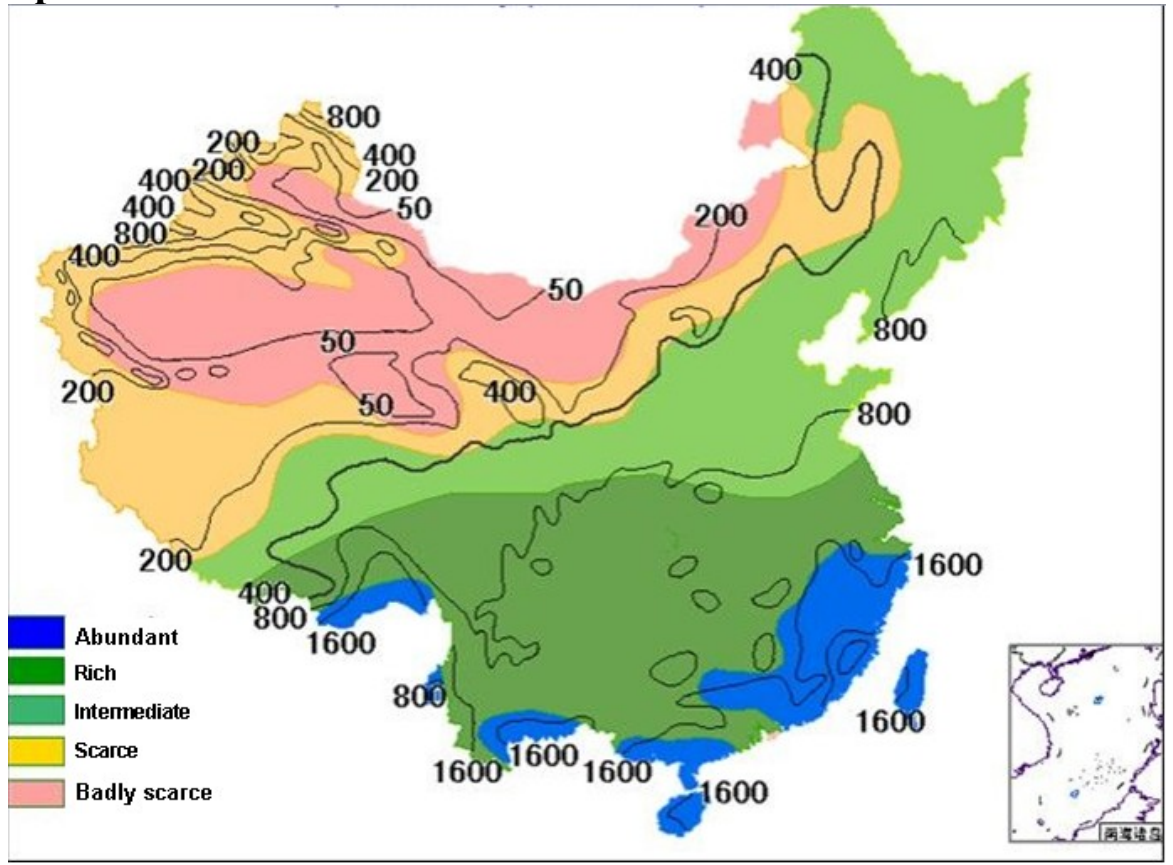

Source: Author

Water is an essential component for both economic growth and well-being of the population. As a traditionally agricultural country, China has to deploy water resources heavily in the agricultural sector where roughly $40 \%$ of inhabitants are employed.

Growing population and intensive economic activities have increasingly threatened the availability and quality of water resources. For social and economic reasons, the government always prioritises the residential and agricultural use of water rather than industrial usage. Water shortage has become a major obstacle to further industrialisation and therefore also to shale gas development.

\subsection{Technology and Service Industry}

The oil and gas industry has learned that unconventional gas development is a "manufacturing business" which involves intensive drilling and fracturing. To a large extent, the capacity and capability of the service industry determines the speed and scale of unconventional gas development. A strong, highly competitive and well-developed service industry provided the North American oil and gas industry with the technical and operational capacity that it needed for its shale gas revolution. Before we discuss the possible replication of the U.S. success story, we need to seriously consider whether China would be able to

\footnotetext{
${ }^{41}$ The areas marked with "abundant" or "rich" are in only in the Chinese context. Bear in mind that China's renewable freshwater resource per capita is less than one-third of world average; vast areas of China are water short compared with other countries.
} 
respond to the industry's call for a major expansion of its service industry as a key component of shale gas development.

The service industry in China is divided among national service companies (NSCs), local private companies and international companies (ISCs). NSCs have around a $60 \%$ market share; local private companies account for $25-30 \%$ and are only hired for services the NSCs cannot deliver. International companies are normally hired for specialised services that neither the NSCs nor the local private companies can deliver and have a 10-15\% market share. The NSCs, associated with the major NOCs, are the strongest service providers in China. They offer everything from land preparation to drilling and completion, including horizontal wells. They also own the majority of the country's 3,500-4,000 land rigs and stimulation equipment. It is expected that NSCs will be expanding their hydraulic fracturing capacities significantly over the coming years in order to fulfil their shale gas production ambitions. The domestic private sector is also growing fast, however, due to its limited financial capacity, it will mainly focus on technical innovations or other services that do not require heavy investments. As the NSCs will probably keep their dominance in the domestic market, the private sector will also try to expand abroad. The ISCs, such as Schlumberger, Halliburton, Baker Hughes, etc. are all present in China through previous field services for conventional oil and gas projects. ISCs have also been actively preparing to penetrate into China's unconventional gas market, but have only so far been involved in providing specific and specialised shale extraction services.

Competition and entrepreneurship are the key drivers of the service industry in the U.S., which in return largely contributes to the sharing of the most advanced techniques and best practices among different operators. However, the market structure of China's service industry, as mentioned earlier, is not remotely comparable to its U.S. counterpart. Major NOCs tend to use their own service companies to carry out field services. The two major onshore operators, CNPC and Sinopec, each have more than ten service subsidiaries. As independent affiliates of the majors, these NSCs dominate the domestic market and have strong bargaining powers against local governments and sub-contractors. They are seldom exposed to the fierce external competition experienced by private service providers; hence they are less innovative and cost-effective than the independent service companies. Although ISCs possess the most technically advanced solutions to field developments, they are often categorised as the most expensive service providers, as they maintain higher international standards than domestic companies. ISCs often find themselves disadvantaged compared with special and long-term relationships which NSCs have with NOCs, and the low costs of independent domestic companies.

The challenges of accessing resources and controlling costs have created a new business model to combine both the technical strength of the ISCs, and the cost and relationship strengths of the NSCs. For example, CNPC's Chuanqing Drilling Engineering Company, provided the majority of field services for a shale gas well drilled by Shell in partnership with CNPC. Chuanqing sub-contracted a few key services, such as horizontal drilling, logging while drilling (LWD), oil based mud (OBM) and multi-stage fracturing, that it could not deliver to ISCs such as Schlumberger and Halliburton, but remains the lead service provider. Such collaboration between ISCs and NSCs helps to control costs along the entire operational chain. Chuanqing, which is familiar with local conditions, was retained as the leading service provider. Meanwhile, Chuanqing managed to utilise the capabilities of ISCs to achieve the operational targets required by the project. 
Drilling and Fracturing Techniques: As mentioned in previous chapters, the key techniques involved in developing unconventional reservoirs are long-reach horizontal drilling and multiple-stage fracturing. China has through its decades of onshore exploration and development accumulated rich experience in onshore drilling. Chinese service companies manage to reduce conventional oil and gas field services costs to a level lower than many other countries, making them competitive in overseas markets. China has also obtained some horizontal drilling expertise from its tight gas development, but lacks significant experience in multi-stage fracturing. In contrast to vertical drilling services, the cost of horizontal drilling and fracturing is much higher in China than in the U.S. For example, the latest horizontal shale gas wells drilled and completed by CNPC in the Sichuan Basin cost approximately USD 11 million, while the average well only costs USD 4-6 million in the U.S. ${ }^{42}$

As already mentioned, the Chinese NOCs have gained knowledge and experience in shale production technologies through partnering with IOCs and ISCs and also through "learning by doing". They are establishing their own research centres and are trying to copy technologies developed by ISCs with the goal of providing the same service in a more costefficient way for both domestic and foreign markets. Due to the larger capacity of the shale gas industry and a steeper ramp-up of activities, total costs are likely to decline more quickly than in other (for example European) countries.

The Supply Chain: Based on the production scenarios in section 4.1, China will need to implement an intensive drilling plan to reach a production level of $50 \mathrm{Bcm} / y e a r$. China needs to drill as many as 1,500 wells in 2019 , and continue to drill approximately 1,000 wells per year for more than a decade. This raises serious questions about the capacity of the supply chain to respond to these demands.

First of all, this level of intensive drilling demands a significant number of land rigs. Drilling and completion advancement and optimisation have shortened the time spent drilling a deep $(2,000-3,000 \mathrm{~m})$ shale gas well. For example, in the Barnett shale, the average total drilling and completion time has been reduced to less than one month. The actual time spent on drilling is normally 15 days. A rig on average drills 12 shale gas wells every year. In China, due to the immaturity of the industry, we assume much lower efficiency - 6 wells/rig/year. China will need approximately 150 to 250 rigs to implement the drilling plan. China currently possesses roughly 3,500-4,000 land rigs and is also one of the major global rig manufacturers, but it will takes a few years before drilling can be increased to the required level of activity. With existing rigs and strong producing capacity, the availability of drilling rigs is not a potential problem that will prevent a rapid increase in shale gas production.

However, China's supply chain faces other bottlenecks that may delay the pace of shale gas development. The challenges are more about quality rather than quantity of supplies. In the past few decades, China has emerged as an important supplier of oil and gas field equipment. Local companies' products not only support domestic conventional oil and gas development, but have also expanded into international markets. For example, by the end of 2010 China was already the largest producer of land rigs with annual capacity of about 1,000 rigs. ${ }^{43}$ However, equipment produced in China is often low-tech. All local equipment manufacturers, although they have been evolving rapidly, lack the capabilities and expertise

\footnotetext{
${ }^{42}$ Source: IEA World Energy Outlook 2011.

${ }^{43}$ Woodmac, June 2011.
} 
to produce advanced equipment required to develop shale gas (such as high-spec fit-forpurpose drilling rigs, frac trucks, frac additives and proppant).

Importing the most technically advanced equipment, such as high-spec rigs and fracturing pumps from major manufacturers in North America, can provide a quick solution in the early years of commercialisation of shale gas development but will significantly increase costs. The Chinese government has set targets to upgrade its service industry to become a major and competitive equipment provider for the global market. ${ }^{44}$ Although such an ambition provides support and business opportunities for domestic service providers and equipment manufacturers, it may result in delays to shale gas development due to the time needed to build sufficient service capacity and the capability necessary for large scale development.

In the longer term, i.e. beyond 2020, we believe the supply challenges will ultimately be overcome as long as the demand from operators is strong. But at the early stage of development, shale gas production may be constrained by lack of the most technically advanced equipment and services as China intends to rely more on domestic rather than international supplies. Importing high-tech equipment from major producers in North America looks economically unfavourable but may emerge as the only feasible solution due to the time needed to upgrade the domestic service industry.

Drilling Crews: Compared with China's manufacturing capabilities and expertise, skilled drilling and fracturing crews may take longer to train. Again, although the country has accumulated similar experience from tight gas development, there is little expertise in shale gas development. The country is short of experienced managers capable of managing large and complex shale gas drilling and completion projects; and skilled labour that is able to operate sophisticated drilling rigs and fracturing pumps. Major NOCs have, through technical exchanges, partnered with IOCs and ISCs gradually obtaining knowledge about shales but such understanding is far too preliminary to be applied directly to commercial production. U.S. experience has demonstrated that efficiency of drilling and effectiveness of stimulation largely determines the ultimate productivity of shale gas wells.

The scale and speed required for intensive shale gas drilling will amplify the challenges of human resources. We believe training skilled drilling crews should be high on the agenda of the major operators. Unless China builds a strong base of skilled workers capable of conducting intensive drilling and fracturing, it is unlikely that shale gas can be rapidly developed. The sooner China can start training capable drilling crews, the faster the country will be able to exploit its shale gas resources.

\subsection{Conclusions}

Based on the analysis in this chapter, we conclude that China will not have a shale gas revolution on the scale seen in the United States; and it is highly unlikely that China will achieve its target of producing $50-80 \mathrm{Bcm} / \mathrm{y}$ of shale gas by 2020 . Even a production level of $30 \mathrm{Bcm} / \mathrm{y}$ by 2020 could be very challenging given the immaturity of the industry and the operational conditions for such large scale development. As of end 2011, the policy makers have set the target of reaching shale gas production to $6.5 \mathrm{Bcm} / \mathrm{y}$ by 2015 . However, we think it will take longer to reach that goal. Our estimate is that China will only manage to produce $5 \mathrm{Bcm} / \mathrm{y}$ (or less) shale gas by 2015 and the production level in 2020 will be approximately $10 \mathrm{Bcm} / \mathrm{y}$.

\footnotetext{
${ }^{44} \mathrm{NDRC}(\mathrm{CBM})$
} 
The major operational obstacles that hamper a quick ramp-up of shale gas are the lack of fresh water in the promising sedimentary basins of north and west China. In areas where fresh water is available, land access can be challenging due to high population density and related economic activities. Both these elements will significantly raise the overall cost of drilling and fracturing. The limitations of the service industry and the lack of adequate pipeline infrastructure, although problematic at the current stage of development, are expected to be resolved over time. Although environmental concerns have not been seriously debated in Chinese society, they are potential show-stoppers. Non-operational bottlenecks, such as fiscal incentives, market access, and managing mineral rights disputes are less visible but equally important. These often involve interests of different stakeholders and therefore take a longer time and more effort to revolve.

Given these significant operational and regulatory challenges facing shale gas exploration and development, we do not expect the shale gas production to have a significant impact even on the Chinese natural gas market by 2020 , let alone the global gas market. More general conclusions will be discussed in Chapter 5. 


\section{General Conclusions}

Since 2005, a so called "shale gas revolution" has swept across North America. Unconventional gas production, especially shale gas production, has already changed the U.S. from a projected major LNG importing, to a potential LNG exporting country with significant impacts on global gas trade. The gas industry has been astonished by the way that large and rapid increases in unconventional gas production have transformed the US energy landscape. This has created tremendous hope that the U.S. story can be replicated in countries with potentially large unconventional resources; China is among these countries.

But before getting carried away with enthusiasm, we need to make an effort to understand how exactly the U.S. model operates and what it implies for countries who want to replicate it. Although technology continues to be the major driver for unconventional gas development in the U.S., the success of shale gas has depended on many other elements that are less visible but equally important, such as the incentives for private landowners, free market access, a mature and competitive service industry, and an extensive pipeline infrastructure.

No other region possesses these favourable conditions and that is probably the reason that shale gas has so far only succeeded in North America. This also indicates that countries with large potential resources that are emerging as promising shale gas producers, still face significant and region-specific challenges that will take time to resolve. North American operators will be very careful in sharing expertise with their counterparts in these countries as it provides their strongest leverage to gain access to new markets. Even when technologies can be exported, those who want to simply copy the U.S. operating model are likely to find such practice inapplicable to their specific business, social and political environment. For example, Geny's analysis ${ }^{45}$ found that for unconventional gas to develop in Europe, European countries would need to create their own business model that different from that of North America.

We therefore believe there has been a general over-enthusiasm concerning the speed with which unconventional gas can be developed beyond North America. As Helge Lund, chief executive of Statoil of Norway, put it in 2010, "it is far too early to conclude whether shale gas will make as much of an impact outside the U.S. as it has done inside the U.S." ${ }^{\text {"4 }}$. Over time, other countries may develop their own method of exploiting their domestic unconventional gas resource. Shale gas development in China clearly reflects the fact that it will be very difficult, or even impossible to replicate the U.S. practices.

Although various sources have estimated that China has one of the largest technically recoverable unconventional gas resource bases in the world, very little exploration has been carried out to confirm its detailed characteristics and productive capacity. It should therefore be emphasised that, despite a potentially large resource base, estimates of how much can be produced and at what cost level may change significantly when further assessments are conducted because the unconventional gas industry, and especially the shale gas sector, is still in its infancy. Beyond 2020, unconventional gas may significantly change China's energy landscape, but for the next decade it is extremely doubtful that volumes of shale gas can be produced in excess of $10 \mathrm{Bcm} /$ year. Whether or not unconventional gas will be developed on a scale that will have a significant impact on the Chinese and global gas

\footnotetext{
${ }^{45}$ Geny 2010

${ }^{46}$ Lund, 2010
} 
markets largely depends on how quickly the government can co-ordinate the interests of different stakeholders in an area where little national experience exists.

The Chinese government has only just started to sort out conflicts over exploration rights between local miners and natural gas producers. The next step is for the government to coordinate the interests of regional governments and NOCs in relation to shale gas development. In this respect, U.S. experience simply does not apply to Chinese conditions. Competing claims to mining rights and land access not only increase the costs of shale gas development, but also limit the possibility for independent gas producers to obtain permission to drill and develop. The United States benefits from a large number of independent gas producers who constantly co-operate and compete with each other on development and implementation of the most advanced technology and best practice. Free market access and competition have reduced costs and increased efficiency. Such effects are unlikely to be replicated in China where the oil and gas industry is dominated by large NOCs seeking to maintain their monopolistic positions. Granting access to other companies could potentially maximise production potential, and introducing foreign operators would speed up development of key techniques and skills, but it seems very unlikely this will happen quickly, if at all.

Unlike in the United States, the dominance of Chinese NOCs over the past few decades has reduced the growth potential of private oil and gas companies and there are only a very small number of regional producers. The government's policies are moving towards more open access for regional and private sector companies, but even if they were granted access to unconventional gas opportunities in China, it is expected that they would only play a limited role in increasing unconventional gas production. The technological, financial and managerial capabilities of regional companies are far less than the giant NOCs. The exploration risks involved are relatively small for NOCs, which are used to large and complex onshore reservoirs, but are difficult to bear for independent Chinese producers. Although the regional players may be able to obtain certain benefits through maintaining good relationships with local governments, they still have a long way to go before they will be capable of producing unconventional gas in a cost-efficient manner - even if this would be less efficient than the NOCs. Regional operators may excel in developing small assets (such as Yanchang Petroleum in Shan'Xi Province), or a specific business opportunity (such as Guanghui's dominance of mini-LNG in Xinjiang province), but cannot transform the country's unconventional gas landscape.

The Chinese government has mixed feelings about cooperation with foreign companies. Despite understanding the potential upside from technology and skill transfers, policy makers in this huge energy-hungry country find it difficult to allow IOCs to share valuable natural resources. As far as NOCs are concerned, on the one hand, they are eager to increase productivity and efficiency using cutting-edge technologies and project management skills through partnership with international operators. On the other hand, given the higher operational standards set by IOCs, such cooperation is likely to end up with much higher costs and longer development time, significantly reducing profits. For these reasons, China tends to rely on domestic operators to develop its unconventional resources. In 2012, the latest news from the NDRC and the MLR was that foreign operators have not been considered as operators of unconventional opportunities, although they are welcome to join through partnership with domestic companies who have been granted foreign co-operation rights. 
As repeatedly emphasised by North American operators, no two shales are identical. Expertise in the optimisation of production can only be acquired through experimentation and experience in each individual play. The geological differences between various shale plays indicate adjustments to, and evolution of, the technology and operational practices applied in North America.

Apart from technological capacity, water usage and land access are the most critical elements that prevent rapid development of its unconventional gas potential. China's high population density and lack of fresh water will largely increase the costs of field development and gas production. Water availability alone rules out the development of a number of sedimentary basins with promising unconventional resource potentials in northern and western China.

Environmental challenges to unconventional gas have so far not been considered a significant issue in China, in contrast to European countries which have raised concerns about the potential damage from intensive drilling and fracturing. China has placed securing gas supply to fuel economic growth much higher on the political agenda than the potential damage the extraction process may create for local eco-systems and communities. However, if it is ever confirmed that intensive drilling and fracturing would cause substantial negative impacts on the health and well-being of local populations, the industry may discover the environmental concerns to be a show-stopper given the people's rising awareness of safety and health.

The analysis in previous chapters leads us to the conclusion that China is unlikely to have a shale gas revolution that will have a huge impact on even the Chinese, let alone the global, gas market by 2020 . Unconventional gas development will see fast growth in this decade, but is still at an early stage and production will not exceed $40 \mathrm{Bcm} /$ year up to 2020 , of which three quarters will be CBM and the rest shale gas. The scenarios in Chapter 3 and 4 suggest that for unconventional gas to have a substantial impact on China's natural gas market, it will need to represent a considerable share of domestic gas production and even reduce the country's dependence on gas imports. However, this study has demonstrated little likelihood of a rapid increase in unconventional gas production. Geological, operational, regulatory and environmental challenges limit China's capacity to quickly unlock its unconventional potential. It is certain that there will be new volumes of gas coming from unconventional reservoirs, but given the country's energy and gas demand growth, these volumes will be absorbed locally.

Table 10 provides estimates of the gas supply and demand balances in China up to 2020 . Domestic conventional production continues to grow, but flattens in the late $2010 \mathrm{~s}$, failing to keep pace with demand. The gas deficit will probably be filled by increasing LNG and pipeline gas imports, rather than by domestic unconventional gas production. Although unconventional gas volumes will increase significantly from 2010 levels, they will have a minor influence on China's dependence on imports, and hence their impact on both domestic and international prices will not be significant. 
Table 10: China Natural Gas Supply and Demand (2011-2020) (Unit: Bcm)

\begin{tabular}{|l|c|c|c|c|c|c|c|c|c|c|}
\hline & $\mathbf{2 0 1 1}$ & $\mathbf{2 0 1 2}$ & $\mathbf{2 0 1 3}$ & $\mathbf{2 0 1 4}$ & $\mathbf{2 0 1 5}$ & $\mathbf{2 0 1 6}$ & $\mathbf{2 0 1 7}$ & $\mathbf{2 0 1 8}$ & $\mathbf{2 0 1 9}$ & $\mathbf{2 0 2 0}$ \\
\hline Demand & 127,3 & 150,7 & 178,4 & 211,2 & 250,0 & 274,6 & 301,7 & 331,4 & 364,1 & 400,0 \\
\hline Growth rate & $18 \%$ & $18 \%$ & $18 \%$ & $18 \%$ & $18 \%$ & $10 \%$ & $10 \%$ & $10 \%$ & $10 \%$ & $10 \%$ \\
\hline & & & & & & & & & & \\
\hline Conventional Production* & 103,6 & 113,7 & 124,7 & 136,8 & 150,0 & 161,9 & 174,8 & 188,8 & 203,8 & 220,0 \\
\hline CBM & 2,1 & 3,1 & 4,5 & 6,6 & 10,0 & 12,5 & 15,5 & 19,3 & 24,1 & 30,0 \\
\hline Shale Gas & - & 0,1 & 0,2 & 0,5 & 1,0 & 1,5 & 2,3 & 3,4 & 5,1 & 10,0 \\
\hline Domestic Supply & 105,8 & 116,9 & 129,4 & 143,9 & 161,0 & 175,9 & 192,6 & 211,5 & 232,9 & 260,0 \\
\hline \hline & & & & & & & & & & \\
\hline Turkmenistan & 12,0 & 15,0 & 22,0 & 25,0 & 30,0 & 30,0 & 35,0 & 35,0 & 40,0 & 40,0 \\
\hline Mynmar & - & - & - & 5,0 & 9,0 & 10,0 & 10,0 & 10,0 & 10,0 & 10,0 \\
\hline Russia & - & - & - & - & - & - & 5,0 & 10,0 & 12,0 & 15,0 \\
\hline Pipeline Imports & 12,0 & 15,0 & 22,0 & 30,0 & 39,0 & 40,0 & 50,0 & 55,0 & 62,0 & 65,0 \\
\hline \hline & & & & & & & & & & \\
\hline LNG imports & 16,9 & 22,2 & 29,1 & 38,1 & 50,0 & 54,2 & 58,8 & 63,8 & 69,2 & 75,0 \\
\hline \hline & & & & & & & & & & \\
\hline Total Imports & 28,9 & 37,2 & 51,1 & 68,1 & 89,0 & 94,2 & 108,8 & 118,8 & 131,2 & 140,0 \\
\hline Supply & 134,7 & 154,1 & 180,5 & 212,0 & 250,0 & 270,1 & 301,4 & 330,2 & 364,1 & 400,0 \\
\hline
\end{tabular}

Source: Author's estimates

China's unconventional gas story is likely to be gradual rather than rapid or game-changing. CBM development in the last 15 years reflects the various challenges which must be met in order to launch its unconventional gas sector. The requirements for large scale unconventional gas development are only at the stage of being defined, and are far from being implemented. North American experience may be useful but will need to be adjusted to local conditions. Rather than replicating the U.S. model, China instead needs to develop practices relevant to its unique industrial, economic, social and environmental realities. The potential for unconventional gas to transform the Chinese market depends very much on how the government manages mining rights, introduces incentive policies, opens market access and deregulates gas prices. Our suggestions would include:

- Financing and guiding R\&D on the assessment and mapping of the resources and the key technologies on horizontal drilling and multi-stage fracturing;

- Managing mineral rights in an orderly manner that harmonises the interests of local communities, oil and gas producers, central and regional governments; introducing incentive policies and regulations to promote unconventional gas exploration and development; deregulating and reforming natural gas price mechanisms to reflect market prices for gas;

- Expanding and optimising pipeline infrastructure to ensure speedy and efficient transportation of gas from producing regions to end users;

- Developing and expanding a strong service industry with the skills and capacities that can keep pace with intensive drilling and fracturing requirements of large scale unconventional gas operations; 
- Considering shale gas development as a good opportunity to upgrade China's manufacturing industry to produce high-tech and high value-added equipment that will be competitive in the global marketplace.

China is among the countries outside the United States which face a reality check on their shale gas ambitions and strategies. Due to the fact that the Chinese government and NOCs play an essential role in the energy sector, the development of China's unconventional gas largely depends on policies which the government may introduce, and how it directs NOCs to unlock unconventional gas resource potential. Nevertheless, for an energy-hungry country striving for stable and secure long term supplies, domestic unconventional gas development remains an attractive option which will continue to be a high priority on China's agenda in the 2010s. It is therefore expected that China will make great efforts to develop unconventional gas in the 2010s and expect these efforts to pay back in the 2020s. Although conventional developments will continue to provide the majority of global oil and gas production, these industries are increasingly evolving towards a more unconventional future. As the world's largest energy consumer, China will need to closely follow these trends. 


\section{Sources}

Aquastat - (www.fao.org). Bernstein Research, 2010

BP 2011 - BP Statistical Review of World Energy 2011

Bernstein Research. Bernstein Asia-Pac Energy: Lift off for

China's unconventional gas revolution. December 2010.

Bernstein Research. Bernstein Asia-Pac Energy: Coal Bed Methane: is it time for China;s unconventional gas revolution. May 2010.

Bernstein Research. Bernstein Asia-Pac Energy: Great Expectations - China kicks off its first shale gas exploration round, July 2011.

China State Administration of Coal Mine Safety, 2010.

CIESIN. Gridded Population of the World. The Earth Institute of Columbia University. 2001

CNPC, Sinopec's presentation at the Ninth/Tenth/Eleventh Sino-US Oil\&Gas Industry

Forum, 2009/2010/2011

EIA - World Shale Gas Resources: An Initial Assessment. April 2011.

EIA - Review of Emerging resources: US Shale Gas and Shale Oil Plays. EIA 2011.

EPA, Feb 2011. "Draft Plan to Study the Potential Impacts of Hydraulic Fracturing on

Drinking Water Resources."

Geny F, Can Unconventional Gas Be a Game Changer in European Gas Markets? December 2010.Oxford: OIES.

Henderson, J. - The Pricing Debate over Russian Gas Exports to China, OIES, September 2011

Hoekstra and Chapagain, 2006. Water footprints of nations: Water use by people as a

function of their consumption pattern. Water Resour Manage.

IEA World Energy Outlook 2010

IEA World Energy Outlook 2011

Luguang Li, CNPC. 2011

Lund, 2010. Europe the New Frontier in Shale Gas Rush. Financial Times, 7 March 2010.

Higashi, Nobuyuki. 2009. Natural Gas in China: Market evolution and strategy. IEA/OECD. Ministry of Water Resources of China, Statistic Bulletin on China Water Activities. 2010.

MLR, 2009 - Zhang Dawei

MLR 2010 - Ministry of Land and Resources, 2010

National Petroleum Assessment (2003-2007)

NDRC, 2011 - "11th Five-Year Plan for Development and Utilisation of Coalbed Methane (Coal Mine Methane)", 2011

RIPED Langfang, CNPC, 2009 - CNPC's Langfang Research Institute

Shengchu Huang, China Coal Information Institute. 2008

Sun, Maoyuan. Energy, December 2009.Woodmac, China Unconventional Gas. June 2010

Woodmac, Natural Gas Long-term View. September 2010.

World Coal Association. http://www.worldcoal.org/

World Economic Forum. 2009. Thirsty Energy: Water and Energy in the $21^{\text {st }}$ Century.

Energy Vision Update.

World Energy Council. 2010. Survey of Energy Resources: Focus on Shale Gas.

Zhang, Kang, China Energy News, Oct 2011 